NBER WORKING PAPER SERIES

\title{
HUMAN CAPITAL AND ORGANIZATIONAL PERFORMANCE: EVIDENCE FROM THE HEALTHCARE SECTOR
}

\author{
Ann P. Bartel \\ Ciaran S. Phibbs \\ Nancy Beaulieu \\ Patricia Stone \\ Working Paper 17474 \\ http://www.nber.org/papers/w17474 \\ NATIONAL BUREAU OF ECONOMIC RESEARCH \\ 1050 Massachusetts Avenue \\ Cambridge, MA 02138 \\ September 2011
}

The authors gratefully acknowledge the generous support of a grant from The Robert Wood Johnson Foundation, outstanding research assistance from Lakshmi Ananth, Bruno Giovannetti, Cherisse Harden, Cecilia Machado, Raymond Lim, Susan Schmitt, Andrea Shane and Anukriti Sharma and helpful comments from Amitabh Chandra, Joseph Doyle, Sherry Glied, Tal Gross, Maria Guadalupe, Samuel Kleiner, James Rebitzer, Jonah Rockoff, Douglas Staiger and Ty Wilde as well as seminar participants at the NBER Summer Institute, The American Society of Health Economists Annual Meetings, MIT, Columbia University Mailman School of Public Health, and CUNY Graduate Center. The views expressed in this paper are those of the authors and do not necessarily represent the position or policy of the Department of Veterans Affairs or the United States government. The views expressed herein are those of the authors and do not necessarily reflect the views of the National Bureau of Economic Research.

NBER working papers are circulated for discussion and comment purposes. They have not been peerreviewed or been subject to the review by the NBER Board of Directors that accompanies official NBER publications.

(C) 2011 by Ann P. Bartel, Ciaran S. Phibbs, Nancy Beaulieu, and Patricia Stone. All rights reserved. Short sections of text, not to exceed two paragraphs, may be quoted without explicit permission provided that full credit, including (C) notice, is given to the source. 
Human Capital and Organizational Performance: Evidence from the Healthcare Sector Ann P. Bartel, Ciaran S. Phibbs, Nancy Beaulieu, and Patricia Stone

NBER Working Paper No. 17474

September 2011

JEL No. I11,I12,J24

\begin{abstract}
$\underline{\text { ABSTRACT }}$
This paper contributes to the literature on the relationship between human capital and organizational performance. We use detailed longitudinal monthly data on nursing units in the Veterans Administration hospital system to identify how the human capital (general, hospital-specific and unit or team-specific) of the nursing team on the unit affects patients' outcomes. Since we use monthly, not annual, data, we are able to avoid the omitted variable bias and endogeneity bias that could result when annual data are used. Nurse staffing levels, general human capital, and unit-specific human capital have positive and significant effects on patient outcomes while the use of contract nurses, who have less specific capital than regular staff nurses, negatively impacts patient outcomes. Policies that would increase the specific human capital of the nursing staff are found to be cost-effective.
\end{abstract}

Ann P. Bartel

Graduate School of Business

Columbia University

3022 Broadway, 623 Uris Hall

New York, NY 10027

and NBER

apb2@columbia.edu

Ciaran S. Phibbs

Health Economics Resource Center (152)

VA Medical Center, 795 Willow Road

Menlo Park, CA 94025

cphibbs@stanford.edu
Nancy Beaulieu

22A Chandler Road

Boxford, MA 01921

nancydeanbeaulieu@yahoo.com

Patricia Stone

Columbia University

School of Nursing

ps2024@columbia.edu 


\section{Introduction}

While economic theory predicts that an organization should perform better when its employees have more human capital, this relationship has been difficult to measure empirically. Measuring an organization's productivity requires detailed micro-level data that is often not available to researchers. ${ }^{1}$ In addition, the definition and measurement of human capital must account for the fact that work is often performed in teams where individual employees use their own knowledge as well as the knowledge of their co-workers to solve problems. ${ }^{2}$ Given this, researchers need to consider not only the roles of general human capital and firm-specific human capital, but team human capital as well. Chillemi and Gui (1997) define team human capital as “effective customs developed by team members." Team human capital enables co-workers to share tacit knowledge and coordinate tasks, thereby allowing the firm to save inputs dedicated to information processing and transmission. ${ }^{3}$

In this paper, we study the relationship between human capital and performance using data on nursing units within hospitals. ${ }^{4}$ This is an excellent setting for studying the relationship between human capital and performance where the work is performed by a team. Nursing units are small; in our sample, a nursing unit has, on average, sixteen patients who are cared for by a

\footnotetext{
${ }^{1}$ Some researchers have studied this relationship using value-added or sales per worker as the measure of productivity. For example, Fox and Smeets (2011) find that human capital measures (education, experience, firm tenure) are important determinants of the dispersion in value-added observed in eight Danish manufacturing and service industries. Black and Lynch (2001) also use sales per worker as their productivity measure in a study that encompasses U.S. firms from a wide range of industries that use very different production processes. In contrast, Ichniowski, Shaw and Prennushi (1997) and Bartel, Ichniowski and Shaw (2007) study firms in a narrowly defined industry, steel finishing lines and valve-making plants, respectively. These two papers are each able to use a precisely defined measure of productivity that is relevant for the plants in their samples.

${ }^{2}$ Hamilton, Nickerson and Owan (2003) and Boning, Ichniowski and Shaw (2007) have studied the impacts of formal teams on productivity in the apparel and steel industries, respectively.

${ }^{3}$ Ichniowski and Shaw (2009) use the term "connective capital" to describe the process by which workers tap into the knowledge of other workers in order to solve problems.

${ }^{4}$ Our paper is best viewed as contributing to the literature on the relationship between human capital and organizational performance. A related literature is the set of studies that have estimated the contribution of firmspecific human capital to individual wage growth (Abraham and Farber 1987; Altonji and Shakotko 1987; Topel 1991).
} 
team of three registered nurses on a given shift, or eight to nine registered nurses on a given day. "Output" is a function not of the effort of a single nurse, but of the combined effort of the nursing team. To measure the output of a nursing unit, we use widely accepted metrics of nursing-sensitive patient outcomes and link them to a set of variables that measure the human capital attributes of the nurses working on the unit. Education and nursing experience prior to joining the hospital are used to measure general human capital while experience in the hospital captures firm-specific, i.e. hospital-specific, human capital. ${ }^{5}$ Team-specific human capital, in this case, nursing unit-specific human capital, is measured by the nurse's experience on a given nursing unit.

Our detailed data enable us to measure changes in the composition of the nursing team on the unit. For example, we are able to identify whether a new nurse joined the nursing team in the month prior to the patient's admission to the unit or whether an experienced nurse left the team during that month. We also consider whether nurses on the team are regular staff members or contract nurses who are not part of the regular nursing team. ${ }^{6}$ Unlike in other contexts where teams are endogenously formed (Bandiera et.al, 2005, 2011), nurses are assigned to units based on existing vacancies. They are compensated based on their seniority and credentials and do not receive individual or group incentive pay. Hence, we do not study the formation of nursing teams or the impact of incentive schemes on individual or team performance as others have done (Bandiera et.al, 2005, 2011) but focus on how exogenous changes in the composition of the nursing team impact patient outcomes.

While the clinical healthcare literature has studied the relationship between the nursing workforce and patient outcomes, these studies are quite limited. The vast majority have used

\footnotetext{
${ }^{5}$ Some researchers have provided evidence that specific skills might be more tied to an industry (Neal 1995; Parent 2000) or an occupation (Kambourov and Manovskii 2009) than to a particular firm. Gathmann and Schonberg (2010) show that human capital may be task-specific and thus transferrable across occupations.

${ }^{6}$ In a study of nurse strikes in New York State, Gruber and Kleiner (2011) found that in-hospital mortality was higher for patients admitted during strikes when hospitals often use contract nurses to replace regular staff nurses.
} 
hospital-level cross-sectional data and have focused on the role of nurse staffing, largely ignoring the impact of various dimensions of human capital and the fact that nursing care is provided in a team setting. ${ }^{7}$ By using the hospital as the unit of observation, these studies do not come close to linking the patients to the actual nursing teams that provided the care nor do they take into account the variance in the patients' level of risk across the diverse units in a hospital. Ours is the first paper to use longitudinal monthly data on nursing units to measure the relationships between the human capital attributes of the nursing team and patient outcomes. ${ }^{8} \mathrm{We}$ are able to do this because we use data from the Veterans Administration (VA) hospital system. Unlike the case for other hospital systems, the VA dataset enables us to link each patient to the nursing units in which he was actually treated. We have data for all patients admitted to acute-care inpatient units in the VA health care system from October 1, 2002 through September 30, 2006. By using data from hospitals belonging to the same umbrella organization that standardizes data collection across its member hospitals, the variable definitions and data coding algorithms are identical across the nursing units in our study. ${ }^{9}$

Since we use monthly data, our parameter estimates are driven by month-to-month variations in nurse staffing and nurse characteristics (education, prior experience, hospital experience, unit experience, contract status), which, unlike year-to-year variations, are likely to be exogenous. Variations in nurse to patient staffing ratios occur for two reasons: unanticipated

${ }^{7}$ For example, see Aiken, Clarke, Sloane, Sochalski and Silber, 2002; Needleman, Buerhaus, Mattke, Stewart and Zelevinsky, 2002, Mark, Harless, McCue \& Yihue, 2004; and Unruh, 2003. Among these studies, the only two that used longitudinal data are Mark et.al. 2004 and Unruh, 2003. Some studies have analyzed the impact of nurse staffing levels on patient outcomes at the level of the nursing unit but these studies are limited because they either do not control for unit fixed effects (Blegen, Goode \& Reed, 1998 and Sales et.al, 2008) or they only study one hospital (Needleman et.al., 2011) .

${ }^{8}$ In a study of British hospitals, Propper and Van Reenen (2010) found that higher outside wages for nurses significantly worsened hospital quality because it was harder to attract and retain skilled nurses. This study did not use data at the level of the nursing unit nor did it consider the impact of nurse tenure.

${ }^{9}$ The VA is known for its state of the art clinical information systems which enables us to develop detailed, accurate measures of nursing-sensitive patient outcomes. The major difference between patients in VA hospitals and patients in non-VA hospitals is that the former do not include children and are only $10 \%$ female. 
nurse absences that cannot be covered through overtime or replacement nurses, and variations in the patient census and patient acuity. Month-to-month variations in nurse characteristics result from nurses taking vacations or leaves, or reaching retirement age, i.e. personal decisions that can be considered exogenous. In the VA, layoffs or terminations are extremely rare events beyond the nurse's six-month probationary period. Reverse causation from voluntary turnover is unlikely with monthly data since nurses do not observe short-term changes in the quality of patient care; this would be a concern with annual data since nurses could arguably observe and respond to annual changes in the quality of care on their unit. Indeed, we show that month-tomonth mobility between units is not correlated with patient outcomes on the unit. In addition, by using monthly data we minimize the potential for omitted variable bias resulting from changes in the management of individual nursing units. In the VA system, these changes are rare, and certainly do not occur on a month-to-month basis; annual data would be more likely to be subject to this type of bias. In sum, our unique monthly data enable us to provide convincing estimates of the impact of various dimensions of nurse human capital on patient outcomes.

We present evidence on two categories of patient outcomes: length of stay and the incidence of a number of complications that have been identified by clinicians as being attributable to nursing care. ${ }^{10}$ Nurse staffing levels and a variety of human capital measures are found to have significant effects on patient outcomes. Higher nurse staffing levels, more general human capital of the nursing staff, and more specific human capital of the registered nursing staff are all associated with shorter patient stays and fewer complications, although the effects on complications are less precisely estimated. The level of specificity of the registered nursing staff's human capital is shown to be an important determinant of patient outcomes. The impact of

\footnotetext{
${ }^{10}$ Both length of stay and the complications we study (pressure ulcers, failure to rescue, infections, and postoperative pulmonary embolisms or deep vein thromboses) have been identified as nursing-sensitive patient outcomes. See Kane et.al. (2007) on length of stay and NQF(2004) on complications. Cook et.al. (2010) studied the impact of California's minimum staffing regulation on pressure ulcers and failure to rescue.
} 
hospital-specific human capital (as measured by tenure in the hospital) is only $22-37$ percent of the magnitude of the impact of unit-specific human capital (as measured by tenure in the nursing unit). Additional evidence of the importance of specific human capital is given by the fact that the presence of contract nurses on the unit, who are not regular members of the unit's nursing team, increases the patient's length of stay and the incidence of complications. Changes in the composition of the nursing team on the unit in which the patient is treated are found to impact patient outcomes; the departure of an experienced nurse is associated with an increase in the patient's length of stay and the arrival of a new nurse is associated with both an increase in the patient's length of stay and an increase in the incidence of complications. We perform a number of robustness checks that support our findings.

Hospitals have been under pressure to reduce costs while maintaining or improving patient outcomes. Since nursing personnel account for two-thirds of hospital labor costs (Rodgers and Lutz, 2003), hospital administrators can be tempted to reduce expenditures on nursing care. We compute the benefits and costs of policies that might be introduced to reduce hospital costs, - such as reducing nurse staffing, reducing the general human capital of the nursing staff by shifting to a larger percentage of unlicensed assistive personnel, reducing the specific human capital of RNs by shifting to a greater percentage of contract nurses or encouraging retirements and hiring new RNs who are paid less. Our analysis shows, that, while decreases in nurse staffing will be cost-neutral, decreasing the human capital of the nursing workforce will not be cost-effective. Personnel costs will be reduced but these savings will be more than offset by an increase in costs due to patients staying longer in the hospital. These findings demonstrate the important role played by human capital in the delivery of healthcare. 
The paper is organized as follows. Section II provides background on the hospital setting and the relevance of various dimensions of human capital. Section III describes the empirical framework and data for our study. Section IV presents the results and Section V concludes.

\section{The Context}

\section{A. Organization of Production}

Hospital patients are assigned to nursing units based on the type of care they require (e.g. acute care units such as medical, surgical, neurology, oncology, and cardiac care, and intensive care units). In our sample, nursing units have, on average, sixteen patients who are cared for by a team of three registered nurses (RNs) on a given shift, or eight to nine RNs on a given day. Registered nurses are assisted by licensed practical nurses (LPNs), and nursing aides or unlicensed assistive personnel (UAPs) who have less extensive educational requirements and clinical training. ${ }^{11}$ While specific RNs are assigned primary responsibility for a patient, some tasks, such as checking certain medications, wound care, or administering blood, require two RNs. In addition, if the primary nurse is busy with another patient or off the unit, other RNs provide help. ${ }^{12}$ Hence, the work on a nursing unit is best described as a group production process that utilizes knowledge workers, i.e. individuals who apply their knowledge to solving specific problems and communicating solutions to co-workers (Garicano and Hubbard, 2007).

The nursing staff provides round-the-clock care for the patients on the unit and is considered the front-line in the provision of care. Nurses are the healthcare providers who identify changes in a patient's condition and the possible need for adjustments in treatment. Patients are also treated by physicians, therapists, nutritionists, and social workers, though the

\footnotetext{
${ }^{11}$ LPNs are not allowed to conduct patient assessments or care planning or administer intravenous medications. UAPs are restricted to very basic patient care tasks.

${ }^{12}$ In addition, nursing care is provided by multiple shifts per day requiring nurses on one shift to share information regarding a patient's condition and treatment with nurses on other shifts.
} 
latter three categories represent a very tiny component of a hospital's labor input. As explained in the empirical section, our analysis focuses on nurses for two reasons: (1) We focus on patient outcome measures that have been shown to be nursing-sensitive, i.e. largely driven by nurses, not other healthcare providers and (2) We study month-to-month changes in patient outcomes at the unit level and the attributes of the nursing team vary by month while the attributes of the other care providers (specifically physicians) change more slowly.

\section{B. Human Capital}

The nursing staff on the unit can be characterized by a variety of human capital attributes. General human capital is higher in units that have a greater proportion of RNs compared to LPNs and UAPs, or a greater proportion of RNs with more prior nursing experience. Since hospitals often use their own systems, policies, procedures and protocols, RNs acquire knowledge and skills that may be specific to the hospital. ${ }^{13}$ Within a hospital, human capital can be specific to the unit in which the RN works, because the nature of care that patients require differs across units and because unit managers are free to establish their own norms and work processes. Survey data on RNs changing jobs suggests that they do indeed acquire significant amounts of hospital-specific and unit-specific human capital. ${ }^{14}$ RNs with longer tenure at the hospital (unit) would be expected to have more hospital (unit)-specific human capital.

Given the round the clock nature of patient care, hospitals must provide adequate nurse staffing at all times, even in the face of significant fluctuations in the patient census. While overtime may be used, many hospitals utilize temporary agency contracts or registry contracts to

\footnotetext{
${ }^{13}$ New technology in the healthcare industry has not yet resulted in standardization of procedures across hospitals. As a result, hospital-specific human capital is still important. For evidence of hospital-specific human capital for cardiac surgeons, see Huckman and Pisano (2006).

${ }^{14}$ In Butt et.al. (2002), nurses changing units and hospitals reported substantial needs for new knowledge in the areas of policies and procedures, patient protocols, technical procedures and nursing interventions. Blythe et.al. (2001) studied nurses changing jobs and concluded that "in an unfamiliar workplace, self-confidence suffered as experienced nurses felt like novices. They had difficulty discovering where things were kept and how equipment worked. They had to adapt to unfamiliar cultural conventions about team work and procedures."
} 
provide adequate nurse staffing. Under an agency contract, the RN is employed by another firm (an agency) but provides nursing services on site at the contracting hospital for a fixed period of time. ${ }^{15}$ Registry nurses (commonly referred to as "per diem" nurses) are essentially a spot market for nursing. Registered nurses who are employed through agency or registry contracts are likely to have less hospital-specific and unit-specific human capital than nurses employed under a traditional employment contract. Contract nurses receive little or no orientation training and are typically brought into the unit on very short notice. Unless they have worked in this unit previously, contract nurses are likely to be unfamiliar with the procedures, practices and equipment in the unit as well as with their nursing colleagues, and are therefore expected to have less specific human capital than regular staff RNs.

Given the group production process on nursing units (where nurses share responsibility for the care of a group of patients), team human capital is likely to play a role in the provision of patient care. Chillemi and Gui (1997) define team human capital as "effective customs developed by team members." Team human capital enables co-workers to share tacit knowledge and coordinate tasks, thereby saving inputs dedicated to information processing and transmission. Unlike other contexts where teams can be endogenously formed (Bandiera et.al.,2011), when a nurse is hired by a VA hospital, he/she is assigned to a unit based on vacancies and mobility between units is rare. In Section III, we show that unit-to-unit mobility is unrelated to patient outcomes and we therefore treat the composition of the team as exogenous. In addition to the uncommon unit-to-unit mobility, team composition can vary from month to month as experienced nurses retire, quit, or take vacation, maternity or personal leaves. If a nurse retires or

\footnotetext{
${ }^{15}$ For evidence of the impact of contract workers in other sectors of the economy, see Rebitzer (1995) and Guadalupe (2003) who find that the use of contract workers is associated with an increased incidence of work accidents and Herrmann and Rockoff (forthcoming) who find that replacing absent teachers with temporary substitutes negatively impacts students' test scores. Autor (2009) provides a broad overview of the rise of temporary help agencies and their impact on the labor market..
} 
quits, she is likely to be replaced by a new employee while in the case of vacation, maternity or personal leaves, the nurse would be replaced by overtime hours provided by other nurses on the unit, by staff nurses borrowed from another unit, or by temporary contract nurses. ${ }^{16}$ The arrival of a new nurse on the unit or the departure of an experienced nurse could affect the functioning of the nursing team if these changes make task coordination or the sharing of tacit knowledge more difficult. For similar reasons, the presence of contract nurses on the unit would be expected to interfere with the functioning of the nursing team.

\section{Production Function}

The output of a nursing unit in a hospital will be modeled as a Cobb-Douglas function where the inputs are labor supplied by nurses (RNs and non-RNs), labor supplied by physicians and other hospital personnel such as therapists, nutritionists and social workers, and a variety of non-labor inputs. "Output" of a nursing unit is best measured as the "shortness" of the patient's length of stay, given his condition upon admission to the unit. Nursing care can affect a patient's length of stay through a number of mechanisms. First, given the patient's condition, length of stay will be shorter if nurses provide better care that produces fewer measurable complications such as infections or pressure ulcers. A second mechanism is through better management of medications, i.e. medications given on time and in the proper doses. Third is through fewer "errors of omission" which may not result in measurable complications but can increase length of stay. Examples are delayed or missed feedings, inadequate hygiene, missed treatments such as ambulating patients or assisting with respiratory hygiene (i.e. coughing and deep breathing after surgery), patient teaching, discharge planning or emotional support (Kalisch et.al., 2009).

\footnotetext{
${ }^{16}$ Regarding contract nurses, Fallik (2005) quotes Dr. Peter Provonost, medical director of the Center for Innovation in Quality Patient Care at Johns Hopkins Hospital who stated that "What we know is that teams who know each other work better than those who don't...And with an agency nurse, it's a new team every day."
} 
Another measure of the unit's output is the frequency of measurable complications such as infections or pressure ulcers.

Physicians will also impact the patient's length of stay but, as explained in the next section, their characteristics are extremely unlikely to vary across the very short time periods that we study. ${ }^{17}$ For simplicity of exposition, we aggregate the non-nurse labor input and the non-labor inputs and define Y as a "positive" patient outcome ("shortness" of stay, or absence of measurable complications), A measures the patient's condition upon admission, $\mathrm{K}$ is a vector that includes the non-nurse labor inputs and the non-labor inputs, and EL is the "effective" nurse labor input:

(1) $\mathrm{Y}=\mathrm{AK} \mathrm{K}^{\alpha} \mathrm{L}^{\beta}$

Effective labor differs from reported labor, RL (the number of nurses), according to equation (2):

(2) $\mathrm{EL}=\mathrm{RL}(1+\lambda \mathrm{HC})$

The human capital attributes of the nurse input (HC) convert reported labor into effective labor according to the index $\lambda$.

Inserting equation (2) into equation (1), we have:

(3) $\mathrm{Y}=\mathrm{AK}^{\alpha}(\mathrm{RL}(1+\lambda \mathrm{HC}))^{\beta}$

Taking logarithms and assuming that $\lambda$ is a small number, results in:

\footnotetext{
${ }^{17}$ Other hospital personnel such as therapists, nutritionists and social workers could impact patient outcomes but they represent an extremely small share of hospital personnel who provide patient care.
} 
(4) $\ln \mathrm{Y}=\ln \mathrm{A}+\alpha \ln \mathrm{K}+\beta \ln \mathrm{RL}+\beta \lambda \mathrm{HC}+\varepsilon$

As explained in the previous section, HC, the human capital of the nursing input, is composed of general human capital, hospital-specific human capital, and unit-specific or teamspecific human capital. In the next section we describe the unique data that are used to estimate an empirical version of equation (4).

\section{Data and Empirical Framework}

\section{A. Data Sources}

We use data from the Veterans Administration Healthcare System which is one of the largest healthcare systems in the U.S. with over 7.2 million veterans enrolled for health services (National Commission of VA Nursing, 2004). During our study period (2003 through 2006) the VA operated 143 hospitals with acute inpatient care units located across the United States. ${ }^{18}$ Although the licensing requirements are the same for VA and non-VA RNs, the VA RN workforce differs from the non-VA's RN workforce in several ways (National Commission on VA Nursing, 2004). It is older (mean age 47.4 versus 45.2 years), slightly more educated ( $34.4 \%$ versus $32.7 \%$ Bachelor's degrees), more ethnically diverse (69.0\% versus $86.6 \%$ White) and has a larger proportion of males (14.3\% versus 5.4\%). To attract and retain nurses, the pay rates of VA nurses are designed to maintain competitiveness in relation to non-VA facilities. According to the Nurse Locality Pay System established under the VA Nurse Pay Act of 1990, the VA pegs the wages of its RNs to the wages of RNs in non-VA facilities in the local labor market (Staiger et al., 2010). ${ }^{19}$ In addition to using the data sources described below, we conducted interviews

\footnotetext{
${ }^{18}$ A few of these VA hospitals do not provide acute care medical services, and hence are not included in our study. ${ }^{19} \mathrm{RN}$ turnover at VA facilities is less than the national average (Department of Veteran's Affairs, 2001; National Commission of VA Nursing, 2004) possibly because the VA pension system calculates pension benefits based on average pay in the final three years of employment. Among the 138 acute-care hospitals in our sample, RN turnover ranged from $3.74 \%$ to $16.61 \%$ in fiscal year 2005 .
} 
with more than fifty nurses and nurse managers from twenty different nursing units in three VA hospitals.

\section{Patient Outcomes}

As previously explained, measuring the impact of human capital on performance in the healthcare sector requires a dataset that links patients to the actual nursing teams that provided their care. The VA hospital system is uniquely qualified for this task. Unlike the system used by most hospitals, the VA's integrated accounting system (DSS) creates a separate electronic discharge record for each "bed section" or "nursing unit" stay for each patient so that it is possible to identify the nursing units in which the patient was treated during his hospital stay. ${ }^{20}$ The Patient Treatment File (PTF) is a patient-level data set that includes the dates of admission and discharge for each bed section as well as the admission and discharge dates for the overall hospitalization. It also includes International Classification of Diseases, $9^{\text {th }}$ version Clinically Modified (ICD) diagnoses.

We use this information to measure patient outcomes in two ways. First, for each patient admitted to a VA hospital during the time period October 1, 2002 through September 30, 2006, we calculate the individual's length of stay in the hospital, a commonly used measure in studies of hospital performance (e.g. Doyle et.al., 2010, Evans and Kim, 2006). Length of stay is a particularly good outcome measure for VA patients. In the VA system, each hospital is paid based on the number of enrollees in the hospital's region and their reported conditions. If an

\footnotetext{
${ }^{20}$ Each bed-section in the hospital corresponds to a type of care, not a specific ward or unit. Care delivered in the ICU is recorded in a separate bed-section record so there is a one-to-one correspondence between bed-section and unit for ICU patients. In the case of general acute care units, there is a single bed-section, for example, for all acute surgical patients even though they could be cared for on more than one surgical ward in larger hospitals with more than one such unit. In our dataset, there is a 1-to- 1 correspondence between unit and bed-section for $89 \%$ of the acute-care bed-section stays. We assigned an additional $6 \%$ of the patients to a specific unit based on the fact that the patient spent less than one day on the second unit; the remaining $5 \%$ of the patients were dropped from the sample. An examination of the excluded patient records showed no systematic differences in the characteristics of the excluded patients.
} 
enrollee is hospitalized sometime during the year, this will not affect the hospital's budget, unless the patient's "condition" is reassessed or the costs of caring for a patient are so high that the patient qualifies for an "outlier" payment. Given each VA hospital's fixed budget, there is a financial incentive to discharge the patient as quickly as is medically appropriate. But, importantly, the VA hospital will not discharge a patient prematurely because the hospital would bear the full financial risk of this decision if the patient subsequently required additional outpatient care or a hospital readmission. This system is different from the private sector in which the discharge decision can be motivated by financial incentives. For example, for each patient admitted to a non-VA hospital, Medicare pays a fixed amount based on the patient's admitting diagnosis; the hospital might then have an incentive to prematurely discharge the patient. $^{21}$ In contrast, Medicaid pays each hospital for each day that the patient is in the hospital and this could incentivize the hospital to keep the patient longer than is medically required.

Second, using the diagnosis codes for each patient, we create a dummy variable that equals one if, during his hospital stay, the patient was diagnosed with any of the following nursing-sensitive complications: (1) Decubitus or pressure ulcers, (2) Infections, (3) Failure to rescue (i.e. death subsequent to an in-hospital complication), ${ }^{22}$ and (4) Post-operative pulmonary embolism or deep vein thrombosis. ${ }^{23}$ Since these outcomes are rare events and are subject to measurement error because they require a healthcare professional to input the information into

\footnotetext{
${ }^{21}$ Some private insurance companies also use this system of paying a fixed amount based on the patient's admitting diagnosis.

${ }^{22}$ Failure to rescue is a better measure of patient outcomes than mortality because it is a conditional outcome measured subsequent to an in-hospital complication (pneumonia, pulmonary embolism, deep vein thrombosis, sepsis,cardiac arrest, gastro-intestinal hemorrhage.) Hence there is less likelihood that the association between nursing attributes and failure to rescue will be confounded by unmeasured patient severity (Silber et.al, 2007). Dobkin (2003) studied in-hospital mortality.

${ }^{23}$ These four complications are called patient safety indicators (PSIs) and were developed by the Agency for Healthcare Research and Quality (AHRQ), although we use the definition of failure to rescue provided in Silber et.al. (2007). Other PSIs that have been identified, but are not considered to be nursing-sensitive, are: Complications of anesthesia, death in low mortality DRGs, foreign body left during procedure, iatrogenic pneumothorax, postoperative hip fracture, postoperative physiologic and metabolic derangements, postoperative respiratory failure, postoperative sepsis, postoperative wound dehiscence, and accidental puncture or laceration.
} 
the data system, less robust effects are likely to be estimated for this dependent variable. We do not have data on medication errors or the "errors of omission" referred to in Section II.

\section{Nursing Input}

Using data from the VA's integrated accounting system (DSS) and its Personnel and Accounting Integrated Data (PAID) which includes employee qualifications and employment history data for all nursing staff, we constructed the variables for the nursing input. From the DSS dataset we extracted monthly data for the fiscal years 2003 through 2006 on the number of nursing hours worked on each unit, for each type of nursing labor tracked by the VA (RN, LPN, UAP). Our measure of nursing hours excludes hours associated with sick, vacation and holiday pay but does include hours that nurses spend outside of patient care, such as participating in training sessions to learn new skills or systems. ${ }^{24}$ The DSS also tracks the number of contract nursing hours charged to each unit, which are largely RN hours. ${ }^{25}$ Using information from the DSS on the number of patient days in each unit in each month, we calculated the hours per patient day worked each month by all nursing staff (RNs, LPNs, UAPs, and contract nurses combined). This is the standard metric used by virtually all hospitals (VA and non-VA) to measure nurse staffing.

The PAID dataset is an individual-level dataset that includes information on each nurse's age, education, prior experience, VA hire date, start date at the VA facility where he/she is currently working, and when the employee started at his/her current nursing unit. It also includes a code indicating each nurse's "time and leave unit" (TLU), which enables us to link each nurse to the unit in which he/she worked during each pay period. We are only able to link nurses to

\footnotetext{
${ }^{24}$ Our measure of nurse staffing excludes nursing management and advanced practice nurses.

${ }^{25}$ The contract nursing hours data do not differentiate between different types of nursing staff, but after examining the wages paid to contract nurses, we concluded that most of the contract nurses during the study period were RNs. For ICUs, over $90 \%$ had hourly costs consistent with RN wages, while about $85 \%$ had RN-level wages in the general acute care units. We do not have any information on the prior work experience of the contract nurses.
} 
their "time and leave unit" as far back as seven years prior to the first month in our dataset, October 2002, resulting in an under-estimate of actual unit tenure for $12 \%$ of the nurses in the dataset. ${ }^{26}$ We correct for the censoring by taking advantage of the fact that there is very little unit-to-unit mobility among the RNs and what mobility does take place occurs in the first few years of the nurse's tenure at the hospital. ${ }^{27}$ For nurses who have censored unit tenure in October 2002, we therefore use their tenure in the hospital (which is not censored) as a proxy for their tenure on the unit. In Part IV, the empirical results are presented with and without this correction.

Using the PAID data, we constructed monthly variables to measure the human capital of the nurses who worked on each unit. Since RNs have more general human capital than LPNs and UAPs, the percentages of nursing hours provided by LPNs and UAPs are used as inverse measures of the general human capital of the nursing staff. General human capital of registered nurses is measured by the average years of the RNs' nursing experience prior to joining the VA. Hospital (or firm) specific human capital is measured by the average hospital tenure of the RNs on the unit. Unit-or-team-specific human capital is measured by the average unit tenure of the RNs on the unit, or the distribution of unit tenure of the RN staff (percentages of total RN hours by RNs who have been on the unit less than 1 year, 1-2 years, 2-3 years, 3-4 years, 4-5 years, 5-6 years, 6-7 years, 7-8 years, $8-9$ years, $9-10$ years and at least 10 years). ${ }^{28}$ The tenure spline enables us to identify if there are diminishing or increasing returns to unit tenure.

\footnotetext{
${ }^{26}$ In October 2002, the first month of FY 2003, if a nurse had started on the unit prior to October 1995, her unit tenure is coded as seven years, and, for each month subsequent to October 2002 that she remains on the unit, her unit tenure is increased accordingly.

${ }^{27}$ For nurses whose unit tenure is not censored, we found that $44 \%$ of their unit changes took place during their first year at the hospital; another $16 \%$ took place in year two and another $10 \%$ took place in year three. Hence, $70 \%$ of the unit changes occurred during their first three years at the hospital.

${ }^{28}$ Tenure categories 10 years and above are grouped because of the very small percentages of nurses who fall into each of the annual categories.
} 
Average unit tenure and the distribution of tenure of RNs varies from month to month as a result of new nurses joining the unit and/or experienced nurses leaving the unit for vacations, leaves, and/or retirements. This turnover is exogenous because nurses do not observe month-tomonth changes in the quality of care; this would be a concern with annual data since nurses could arguably observe and respond to annual changes in the quality of care on their unit. ${ }^{29}$ In addition, we show below that monthly unit-to-unit mobility is less than $1 / 2$ percent and, importantly, is unrelated to characteristics of the unit.

The percentage of RN hours provided by contract nurses is also used as a measure of the specificity of human capital of the registered nursing staff. Finally, we use the average wage of the registered nursing staff as another proxy for skill. ${ }^{30}$

\section{Other Variables}

We use two variables to control for the severity of each patient's condition upon admission to the unit: (1) Medicare's median length of stay for the patient's admitting $\operatorname{diagnosis}^{31}$ and (2) information from the Patient Treatment File to calculate the patient's Elixhauser et.al. (1998) index, a sum of the patient's co-morbidities. An additional case-mix adjuster created from the Patient Treatment File is the patient's age. ${ }^{32}$ We do not have data on the characteristics of the physicians in the unit but the absence of this information does not bias our results. In the VA hospitals, physician teams are assigned to nursing units but, importantly, these

\footnotetext{
${ }^{29}$ During the nurse's first six months at a VA hospital, he/she is considered to be on probation and can be terminated for poor performance. After the first six months, it is extremely unlikely to observe terminations for poor performance.

${ }^{30}$ The average RN wage is calculated as the sum of wage costs for all RNs in the unit in that month divided by total $\mathrm{RN}$ hours in that month which equals regular hours+vacation/holiday hours $+(1.5 *$ overtime hours $)$.

${ }^{31}$ Some prior studies have used the Medicare DRG weight to control for the severity of the patient's condition. This variable is based on the cost of procedures associated with the condition and high-cost procedures which may be unrelated to the severity of the patient's condition play a large role in the calculation of the DRG weight. The Medicare median length of stay is a better measure of the severity of the patient's condition. The regressions presented in Section IV were also estimated using the Medicare DRG weight in place of the Medicare expected length of stay and the results were virtually identical.

${ }^{32}$ We do not have information on the patient's gender or race but as indicated in footnote $9,90 \%$ of the VA patients are male.
} 
assignments do not vary on a monthly basis (although they might change every year or two). ${ }^{33}$

The characteristics of the physicians on the team in the unit do not vary on a month to month basis because, even if a particular physician is absent during a month, the patients are cared for by other members of the physician's team and there is substantial evidence of significant homogeneity in the practice styles of physicians who belong to a given team. ${ }^{34}$ To account for the possibility that more senior physicians might take vacations during certain months, our regressions will include month fixed effects. Apart from the seasonality factor, we have no reason to believe that physician characteristics will be correlated with month-to-month variations in nurse characteristics. This, in combination with the evidence on uniform practice styles within physician groups, means that the absence of data on physician characteristics should not bias our results. The nursing unit annual fixed effect controls for $\mathrm{K}$, the non-nurse labor input and the non-labor input in the unit, as well as nurse manager characteristics, which are unlikely to vary on a month-to-month basis.

\section{Summary Statistics}

Table 1 shows summary statistics for the variables used in the analysis. All of the standard deviations in Table 1 are large relative to the means and there is substantial withinnursing unit variation in these variables, lending support to using a fixed effects framework. The mean length of stay in the hospital is six days and the incidence of reported complications is $2 \%$. Mean nursing hours per patient day is 12.6 which is consistent with findings outside of the VA (Needleman et.al, 2002). Twenty-five percent of nursing hours are provided by non-RNs (LPNs and UAPs) and contract nurses account for, on average, 2 percent of nursing hours with a wide variation across units; these numbers are consistent with findings outside of the VA (Furukawa

\footnotetext{
${ }^{33}$ Doyle, Ewer and Wagner (2010) used data from one VA hospital where they were able to identify the physician teams that treated each patient. This information was only available for one hospital.

${ }^{34}$ See Dartmouth Medical School's Institute for Health Policy and Clinical Practice.
} 
et.al., 2010). Using the version of unit tenure that is censored for $12 \%$ of the RNs, average unit tenure is 4 years; correcting for censoring raises the average to 5.23 years. $^{35}$

\section{B. Empirical Model}

The framework in equation (4) showed that a unit's "output" can be modeled as a function of the characteristics of the nurses (and other inputs) on the unit as well as the patients' characteristics. As explained above, we have monthly data on nursing units and one approach to estimating equation (4) is to link monthly average patient outcomes on the unit to the monthly average characteristics of nurses on the unit and the monthly average patient characteristics. When length of stay is used to measure a unit's output, this approach is potentially problematic for the following reason. The metric used in virtually all hospitals to measure a nursing unit's staffing is nursing hours per patient day where the numerator is the total nursing hours on the unit and the denominator is the number of patient days on the unit that month. In our analysis, we also use this metric to measure nurse staffing.

Month-to-month variations in hours per patient day are driven by three factors: the number of nursing hours available, the number of admissions, and the severity of the admitted patients' conditions or their expected length of stay. While nurse schedules are usually set six to twelve weeks in advance based on the predicted census for the unit, the actual nursing hours available are affected by unanticipated nurse absences that cannot be covered through overtime or the use of contract nurses or nurses floated from another unit. Similarly, month-to-month variations in a nursing unit's admissions are exogenous.

With regard to the expected length of stay, there could be a potential source of bias. If our measures of patient acuity (Medicare's predicted length of stay given the patient's diagnosis,

\footnotetext{
${ }^{35}$ The tenure spline variables are based on the version of unit tenure that is corrected for censoring.
} 
the Elixhauser index of co-morbidities and the patient's age) do not perfectly control for the severity of illness, the expected length of stay may vary with this unobserved severity of the patient's underlying disease. If nurse staffing is not or is unable to be adjusted for this increase in the demand for nursing hours, then there could be an endogenous relationship between hours per patient day and length of stay. In order for this endogeneity story to be valid, there would have to be a systematic difference in unobservable patient attributes at the unit level that affect both the average length of stay and hours per patient day. This could be at least partially remedied by including a unit fixed effect which captures the unobservable attributes of the unit's patients (i.e. each unit treats a specific type of condition). The endogeneity story would require that in some months, the unit systematically admits patients whose acuity is not accurately measured by our three control variables and that simultaneously the unit is unable to adjust nurse staffing to meet the unobserved changes in the need for nursing labor.

We analyzed the within-unit month-to-month variance of hours per patient day to determine which component is driving the variation. Appendix Table A-1 shows the contributions of LOS (column 1) and 1/LOS (column 2) compared to the contributions of nursing hours and admissions. Controlling for patient acuity, length of stay (LOS) explains less than $1 \%$ of the variance in hours per patient day while $1 /$ LOS explains $4 \%$ of the variance (compare rows 1 and 2). Adding additional controls for nursing hours or admissions, we also find that LOS only explains $1 \%$ of the variance in hours per patient day (compare rows 3 and 5 , 4 and 6 , and 7 and 8 ) while $1 / \operatorname{LOS}$ explains between 1 and $5 \%$ of the variance. The variance in hours per patient day is more sensitive to changes in admissions but is largely driven by changes in nursing hours.

Based on this, we believe that the potentially endogenous relationship between length of stay and hours per patient day is unlikely. However, to avoid any potential endogeneity bias we 
estimate a patient-level version of equation (4) in which the dependent variable is the patient's total length of stay in the hospital and the unit characteristics refer to the first unit on which the patient was treated. This approach has two advantages. First, if a patient is unobservably sicker and requires a longer stay, the added stay of this one patient will have a small effect on the hours per patient day in the unit in which he was first treated. ${ }^{36}$ Second, since $25 \%$ of the patient stays in our sample span more than one unit, this also weakens the potential spurious correlation between the denominator of the staffing variable and the dependent variable. Note that when we use the incidence of complications as the dependent variable, the potentially spurious relationship does not exist. ${ }^{37}$ Another justification for linking the patient's total length of stay to characteristics of nurses on the first unit is that patients tend to be sickest when they first enter the hospital. If they get worse over time, moving for example from a general acute care unit to a unit that provides more intensive care, this is usually due to something going wrong in the first unit.

We estimate the following regression for all patients admitted to acute care units in VA hospitals during the time period October 1, 2002 through September 30, 2006:

$$
\mathrm{Y}_{\mathrm{it}}=\alpha_{1} \mathrm{~S}_{\mathrm{ijt}}+\alpha_{2} \mathrm{HC}_{\mathrm{ijt}}+\alpha_{3} \mathrm{P}_{\mathrm{it}}++ \text { Month }+\mathrm{U}_{\mathrm{jyr}}+\mu_{\mathrm{it}}
$$

where $Y_{i t}$ is either the patient's length of stay in the hospital or an indicator for complications the patient developed during the hospital stay. $\mathrm{S}_{\mathrm{ijt}}$ and $\mathrm{HC}_{\mathrm{ijt}}$ measure the attributes of the nursing staff in month $t$ of the unit $\mathrm{j}$ to which patient $\mathrm{i}$ was admitted. $\mathrm{S}_{\mathrm{ijt}}$ is the staffing measure for the unit to

\footnotetext{
${ }^{36}$ The average patient census on a unit is sixteen.

${ }^{37}$ Even in this case, however, using the average characteristics across all units would not be appropriate. For example, if low staffing in the first unit resulted in the patient getting an infection which then resulted in a transfer to a unit that provides more intensive care, linking the incidence of the complication with the average characteristics of all units on which the patient was treated would result in an underestimate of the true effect of low staffing on the incidence of the complication.
} 
which the patient was admitted; as described above, this is defined as total nursing hours per patient day. $\quad \mathrm{HC}_{\mathrm{ijt}}$ is the vector of variables measuring the general human capital of the nursing staff (percentages of nursing hours provided by LPNs and unlicensed assistive personnel (UAPs), and average prior experience of RNs), hospital-specific human capital of RNs (average tenure in the hospital), unit-or-team-specific human capital of RNs (average tenure on the unit or the tenure distribution, and percentage of nursing hours provided by contract nurses). Patientlevel variables, $\mathrm{P}_{\mathrm{it}}$, are the Medicare expected length of stay, the Elixhauser index of comorbidities, and the patient's age. Referring back to equation (4), $\mathrm{P}_{\mathrm{it}}$ captures the "In A" term. Month is a vector of 47 month dummies (November 2002 through September 2006) that measure time-varying effects that are common to all units. ${ }^{38}$ The random, unobserved error component is denoted as $\mu_{\text {it. }}$ Robust standard errors are clustered at the level of the nursing unit.

The panel nature of our data enables us to include nursing unit fixed effects that vary by year, denoted $U_{\mathrm{jyr}}$, in equation (5). These fixed effects control for any characteristics of the nursing unit that might influence patient outcomes such as the manager of the unit or the nonnurse labor characteristics of the unit (e.g. attributes of physicians or other hospital personnel) or the non-labor inputs (e.g. number of beds, technology) that do not vary within a year. ${ }^{39}$ Referring back to equation (4), the variable "In $\mathrm{K}$ " is captured by the annual unit fixed effect. The fixed effect also controls for the type of nursing unit (e.g. medical, surgical, neurology, oncology, infectious diseases, intensive care) and hence, the average patient acuity on the unit, and the characteristics of the hospital (e.g. teaching status) and the local labor market. Our parameter estimates are driven by month-to-month variations in nurse staffing and nurse characteristics which are likely to be exogenous.

\footnotetext{
${ }^{38}$ In order to account for the fact that many, but not all, VA hospitals are teaching hospitals and new resident doctors have a learning curve, we also added a set of interaction terms between the month dummies and the teaching status of the hospital. This had no impact on the results shown in Section IV.

${ }^{39}$ Referring back to equation (4) in Section II, the variable K is captured by the annual nursing unit fixed effect.
} 
Month-to-month variations in nurse characteristics such as the percentage of nursing hours that are RN hours, average unit tenure, and percentage of contract hours, result from nurses calling in sick, taking vacations or leaves, or reaching retirement age, i.e. personal decisions that can be considered exogenous. Unit-to-unit transfers within hospitals are rare; the monthly unitto-unit mobility rate is less than $1 / 2$ percent. We estimated mobility regressions where the unit of observation is the $\mathrm{RN}$ and the dependent variable equals one if the $\mathrm{RN}$ is working in a different unit in time period $t+1$ compared to time period $t$. Independent variables, measured as of time $t$, are tenure on the unit, age and education, and unit characteristics (hours per patient day, average length of stay, admissions, percentage of nursing hours that are non-RNs, percentage of nursing hours provided by contract RNs, and patient acuity). The regression results, shown in Appendix Table A-2, indicate that unit-to-unit mobility is not correlated with patient outcomes (length of stay) on the unit. This makes sense since nurses are unlikely to observe month-to-month variations in patient outcomes on their units which might lead them to request transfers or call in sick; using monthly data therefore makes reverse causation very unlikely.

Figure 1 shows the month-to-month within-unit residual variation (after controlling for the annual unit fixed effect and the month time dummy) in the dependent and independent variables. Reassuringly, these figures do not show any obvious trends. Appendix Table A-3 shows the results of Box-Pierce tests that confirm that all of the series are "white noise".

Finally, we conducted a randomization analysis to consider if there is a relationship between the severity of the patient's condition and the characteristics of the nurses in the unit to which he/she is admitted. For example, it could be the case that in some months patients on the unit are sicker and these happen to be the months when the more experienced nurses are on vacation. Table 2 presents regressions in which the dependent variable is either the Medicare expected length of stay given the patient's diagnosis or the value of the Elixhauser index which 
captures the patient's co-morbidities. Columns (1) and (3) do not include unit fixed effects while columns (2) and (4) do. Importantly, we find that controlling for the annual unit fixed effects, there is no correlation between the patient's condition at admission to the unit and the characteristics of the nurses on the unit.

\section{Results}

\section{A. Length of Stay}

The final dataset included 1,568,034 patients who were admitted to 472 nursing units in 129 different VA hospitals. ${ }^{40}$ The results of estimating several variants of equation (5) are shown in Table 3. In columns (1) - (3) the censoring of unit tenure is not corrected and in columns (4)-(6) the correction described in the previous section is used. A one hour increase in nursing hours per patient day is associated with a 1.4 percent reduction in length of stay. We have three indicators of general human capital: two inverse measures based on the percentages of nursing hours provided by LPNs or UAPs, and average RN nursing experience prior to joining the VA, but only one, percentage UAPs, is significant. The positive and significant coefficient on UAP means that an increase in the general human capital of the nursing staff through a ten percentage point reduction in the share of nursing hours provided by UAPs is associated with a 1.1 percent decrease in length of stay.

Hospital-specific human capital of RNs is proxied by the variable "average facility tenure minus average unit tenure" and unit or team-specific human capital of the RNs is measured by the average unit tenure or a tenure spline that captures the distribution of unit tenure of the RNs

\footnotetext{
${ }^{40}$ Given the requirement that a nursing unit must be staffed by at least one nurse at all times, we observed that when patient days dropped below 100, hours per patient day became very unstable. Therefore, monthly observations for units with less than 100 patient days were excluded. In addition, after screening the hours per patient days data for obvious errors and consulting with the chief nursing officer of the VA, we excluded any month if reported hours per patient day was $<12$ or $>48$ for intensive care units and $<3$ or $>15$ for acute care units. A unit was entirely excluded if more than half of the months for that unit were excluded.
} 
on the unit. In columns (1), (3), (4), (5) and (6), holding average unit tenure or the distribution of unit tenure constant, the additional facility tenure net of unit tenure is insignificant. Average unit tenure has a negative and significant effect on length of stay in columns (1) and (4); an increase of one year in average unit tenure of RNs on the unit is associated with a 1.3-2.3 percent reduction in the patient's length of stay depending on whether censoring of unit tenure is corrected (Column 4) or not (Column 1). In column (2), average facility tenure is used in place of its components, average unit tenure and facility tenure outside of this unit. While significant, the coefficient on average facility tenure in column (2) is only $22 \%$ the size of the coefficient on unit tenure in column (1) and 37\% the size of the coefficient on unit tenure in column (4). Unit or team-specific human capital of RNs is a much more important determinant of the patient's length of stay than hospital-specific human capital.

In columns (3) and (5), we replace average $\mathrm{RN}$ unit tenure with a tenure spline where the excluded category is percent of RN hours with less one year of tenure on the unit. All of the coefficients on the tenure spline variables are negative and significant in both columns. In Panel A of Figure 2, we plot the coefficients on the tenure spline from Column 4 (where the censoring of unit tenure is corrected). ${ }^{41}$ The figure also shows regression lines that were fitted to the tenure spline coefficients using either a linear or quadratic specification for tenure. We find a large return to unit tenure after the first year on the unit; holding constant the percentages of RN hours in the "2 plus" categories, a 10 percentage point increase in the share of RN hours with 1-2 years of unit tenure is associated with a 0.6 percent reduction in length of stay. A similar increase in the 2-3 category is associated with a 1 percent reduction in length of stay. What is noticeable about the tenure spline is that the returns to tenure diminish somewhat in the three to seven year

\footnotetext{
${ }^{41}$ Using information on the percentages of RN hours in each of the annual categories that comprise the $10+$ tenure category and assigning the midpoint of each interval as the average value of tenure in that category, (e.g the 10-11 category is assigned a value of 10.5), and assigning 20 to the open-ended interval, we calculated that the mean value of tenure associated with the $10+$ category is 15.69 . The coefficient on the open-ended category is therefore plotted in Figure 2 as being associated with a tenure value of 15.69.
} 
range and then increase, followed by a slight leveling off at the $10+$ category. Panel B of Figure

2 shows an alternative spline in which we group the categories 8-9 and 9-10 years of tenure

because the means for these categories are small (below 5\%). The patterns in Panels A and B are quite similar. One possible interpretation of the finding that the returns to tenure increase after seven years is that senior nurses may be mentoring nurses who are new to the unit. In sum, Table 3 shows that patient outcomes (as measured by length of stay) are better in units that are staffed by RNs whose average unit tenure exceeds one year, and this beneficial effect does not diminish with unit tenure. ${ }^{42}$

An additional measure of specific human capital is the percentage of contract nursing hours. Table 3 shows that a 10 percentage point increase in the share of nursing hours provided by contract nurses (which is almost equivalent to replacing one regular $\mathrm{RN}$ with a contract nurse) is associated with a significant 2.1 percent increase in length of stay. ${ }^{43}$ We analyzed the determinants of the use of contract nurses and found that contract nurses are more likely to be used when regular RNs are on vacation, sick or not working because of a holiday. ${ }^{44}$ Table 3 shows that replacing regular RN staff with contract nurses interferes with the efficient functioning of the unit in that patients with given diagnoses stay longer on the unit. Although we cannot definitively distinguish whether the contract nurse effect is due to contract nurses having

\footnotetext{
${ }^{42}$ In the economics of education literature, returns to teacher experience have been estimated but these studies have been unable to distinguish between returns to general and specific human capital, i.e. they do not distinguish between teaching experience at the current school and elsewhere. Rockoff (2004) finds that teaching experience improves reading test scores but in the case of math tests, it is only the first two years of teaching experience that raise student performance. Rivkin, Hanushek and Kain (2005) find that beginning teachers perform significantly worse than more experienced teachers with minimal additional gains after the first year.

${ }^{43}$ In our dataset, there are, on average, three RNs per eight-hour shift, or nine RNs per day. Replacing one of these RNs with a contract nurse would be equivalent to an eleven percentage point increase in the share of nursing hours provided by contract nurses.

${ }^{44} \mathrm{We}$ estimated a regression of percent contract hours on hours per patient day, admissions, $\mathrm{RN}$ vacation/sick/holiday hours as a percent of total nursing hours, time dummies and unit fixed effects. Holding constant admissions and hours per patient day, a 10 percentage point increase in the share of vacation/sick/holiday hours is associated with a 4 percentage point increase in the percentage of nursing hours provided by contract nurses. Contract nurses are also used when admissions increase, but the magnitude of this effect is very small (doubling admissions from 100 to 200 per month is associated with 0.04 percent increase in the percentage of contract hours.
} 
less hospital-specific capital, less unit-specific capital, or both, the fact that facility tenure had a much weaker impact than unit tenure for regular RN staff would suggest that the contract nurse effect is also largely due to contract nurses having less unit-specific capital.

In column (6) of Table 3, we add the average wage of RNs on the unit in that month. This variable is insignificant; the fact that the VA uses a rigid wage scale means that wages are essentially a proxy for tenure and multicollinearity is the likely explanation for the insignificant coefficient on the average wage. In a regression not shown here, we found that, deleting unit tenure and facility tenure resulted in a negative and significant ( 5 percent level) effect of the average $\mathrm{RN}$ wage on length of stay.

Our detailed longitudinal data enable us to consider how changes in the nursing team impact length of stay and these findings provide additional evidence on the importance of specific human capital. Columns (1) and (2) in Table 4 show that if the patient is admitted to a unit in a month in which an experienced (at least one year of unit tenure) nurse had departed during the prior month, length of stay is greater. Columns (3) and (4) report stronger impacts on length of stay if the departing nurse had at least five years of tenure on the unit. Table 4 also shows that if a new nurse joined the unit and hospital in the month prior to the patient's admission, length of stay is higher. But, the arrival of a nurse from another unit in the hospital does not impact length of stay. It is important to note that including the various indicators for changes in the nursing team does not impact our previous findings that unit tenure of RNs is associated with shorter lengths of stay and the use of contract nurses is associated with longer lengths of stay. This lends support to interpreting the effects of unit tenure and contract nurses as indicators of changes in human capital rather than disruptions to the nursing team.

\section{B. Robustness Checks}


In this section, we report the results of a number of robustness checks shown in Table 5. Columns (1) through (4) in Table 5 use the specification in column (4) of Table 3 and columns (5) through (8) use the specification in column (1) of Table 4. The first robustness check is to restrict the analysis to the months in which the regular staff RNs and especially RNs with seniority are likely to take vacations; changes in average unit tenure and the use of contract nurses are most likely to be driven by the exogenous behavior of the RNs during these months. This robustness check is especially useful for the following reason. We argued earlier that using monthly data rather than annual data is preferable because annual variation can be endogenous (e.g. timed changes in the management of units or assignment of physician teams). While this variation could still potentially impact the monthly variation, it will be swamped by the more exogenous variation that occurs during the vacation months. An analysis of the vacation patterns of the RNs indicated that the relevant months are August, December and January. The results of this robustness check are shown in columns (1) and (5).

In the second robustness check, shown in columns (2) and (6), we exclude the observable characteristics of the patients (Medicare expected length of stay, Elixhauser index and age). If the parameter estimates are not affected by these exclusions, we can more safely conclude that absence of information on the unobservable attributes of the patients does not bias our results. The third robustness check, shown in columns (3) and (7), is to restrict the analysis to patients whose stay on the unit was entirely within the month under study, i.e. to eliminate patients whose stay may have started at the end of month and ended at the beginning of another month, and who therefore may have been cared for by a different team of nurses. Finally, in the fourth robustness check, shown in columns (4) and (8), we restrict the analysis to patients whose hospital stay spanned more than one unit. Referring back to the discussion on page 19, for this group of 
patients the potential spurious correlation between the denominator of the staffing variable and the dependent variable is significantly weakened or eliminated.

It is reassuring that the coefficients on nurse staffing, contract nurses, and average unit tenure are significant in all the specifications in Table 5. The use of unlicensed assistive personnel (UAPs) is significant in three of the four robustness checks, the exception being the restriction to vacation months. The addition of a new nurse to the unit and facility is significant in three of the four robustness checks, the exception being the restriction to patients who stayed on multiple units. The departure of an experienced nurse remains significant except when the analysis is restricted to vacation months. In sum, our main findings regarding the importance of specific human capital are robust. ${ }^{45}$

\section{Complications}

As explained in Part II, given a patient's condition, his length of stay will be shorter if nurses provide better care that produces fewer complications such as infections or pressure ulcers, fewer medication errors, and more efficient coordination of care across multiple providers (e.g. nutrition, physical therapy, social work) that can facilitate timely discharges. In this section, we consider the first mechanism; we do not have data that enable us to test the second or third mechanisms. Tables 6 and 7 present results from regressions in which the dependent variable equals one if the patient was reported to have any of the four nursing-sensitive complications identified in Part III. A previous study (Needleman et. al., 2002) that used hospital-level data to examine the relationship between some of these measures and nurse staffing did not find robust results, even though a cross-sectional framework was used. ${ }^{46}$ This is because these complications are extremely rare events. The fact that we are using a more precise

\footnotetext{
${ }^{45}$ In columns (1) and (5) in Table 5, the coefficients on percent LPN hours are negative whereas they were positive in Table 3. But, just as in Table 3, the usage of LPNs has an insignificant effect on length of stay.

${ }^{46}$ In their study of the California minimum staffing law, Cook et.al. (2010) also found insignificant effects of nurse staffing ratios on complications.
} 
method of estimation, i.e. including unit-level fixed effects, makes it even less likely that we will find systematic effects. ${ }^{47}$

The results in Table 6 show that complications are less likely to occur as nursing hours per patient day increases and are more likely to occur as the percentage of nursing hours provided by unlicensed assistive personnel increases (i.e. as the percentage of hours provided by RNs decreases), though the significance levels are smaller than in the corresponding length of stay regressions. The magnitudes of these effects are also quite small but it is important to remember that complications are rare events and the mean of the dependent variable is only $0.02{ }^{48}$ In addition, we find some evidence that increases in specific human capital are associated with a lower incidence of complications. The contract nurse variable is significant in five of the six columns while average unit tenure is significant in column (1) only. ${ }^{49}$ The relationship between the tenure spline and complication does not mirror the linear relationship found in Table 3. Table 7 shows that, when considering the effects of changes in the nursing team, it is only the addition of a nurse who is new to the hospital and unit, not the departure of an experienced nurse, that raises the incidence of complications. In sum, while the results in Tables 6 and 7 are much weaker than those reported in Tables 3 and 4, there is an association between the incidence of complications and nurse staffing levels, the use of unlicensed assistive personnel, the use of contract nurses and unit tenure of RNs.

\section{Cost-Benefit Calculations}

\footnotetext{
${ }^{47}$ The regressions in Tables 6 and 7 were estimated as linear probability models because we were unable to get the fixed effects logits to converge.

${ }^{48}$ Increasing hours per patient day by one lowers the incidence of complications by $0.02 \%$; raising the percent of UAP hours by 10 percentage points raises the incidence of complications by less than $0.1 \%$.

${ }^{49}$ Increasing the percent of contract hours by 10 percentage points raises the incidence of complications by less than $0.1 \%$.
} 
Table 3 shows that length of stay can be reduced by increasing nursing hours per patient day, reducing the percentage of nursing hours that are supplied by unlicensed assistive personnel and/or contract nurses, or increasing average unit tenure of RNs. By using data from the VA on RN wages, LPN wages, UAP wages, contract nurse wages, and the VA's calculation of the average daily cost per day of stay in the hospital, we can calculate the cost-effectiveness of these policy changes. Table 8 shows the results of these calculations which are based on the coefficients from column (4) in Table 3. The costs and benefits are calculated on a per-patient basis.

The benefit of increasing hours per patient day by ten percent (i.e. by 1.26 hours) is calculated by multiplying the mean length of stay times the effect on length of stay of an increase in hours per patient day times the cost of a day in the hospital (the average of which is $\$ 2531$ in our dataset). ${ }^{50}$ The cost of increasing hours per patient day is calculated by assuming that the skill mix of nurses remains constant (75\% RNs, 14\% LPNs, and 11\% UAPs) and then using these weights to calculate the median hourly wage of the entire nursing staff. This median wage (\$38) is then multiplied by the mean length of stay. According to the results in Panel A, costs exceed benefits by $\$ 10$ per patient, an extremely negligible amount given the average daily cost of \$2531. Panel B calculates the benefit and cost from reducing the UAP share of nursing hours by 10 percentage points and increasing the $\mathrm{RN}$ share by 10 percentage points. Benefit calculations follow the same approach as in Panel A and the cost calculation multiplies hours per patient day times mean length of stay times the difference between RN median wages and UAP median wages. This change is marginally cost-effective, with benefits exceeding costs by $\$ 10$ per patient. Panel $\mathrm{C}$ follows the same approach as Panel B and calculates the benefit and cost from reducing the contract share of nursing hours by 10 percentage points and increasing the

\footnotetext{
${ }^{50}$ The cost of a day includes all direct and indirect costs including nurses, MDs, costs of all equipment, lab tests, medications, images, food, housekeeping and administration.
} 
regular RN share by 10 percentage points. This change is extremely cost-effective with benefits exceeding costs by $\$ 277$ per patient. Finally, Panel D considers the cost and benefit of increasing average $\mathrm{RN}$ unit tenure by one year, from its current mean. The benefit calculations follow the same approach as in Panel A and the cost calculation uses data on RN median wages by years of unit tenure. This change is also cost-effective, with benefits exceeding costs by $\$ 32$ per patient. In sum, we find that an increase in hours per patient day is essentially cost- neutral as is an increase in the general human capital of the nursing staff (i.e. decreasing UAP), while increasing the specific human capital of the $\mathrm{RN}$ staff by decreasing the usage of contract nurses or increasing unit tenure of RNs are both cost-effective. It is important to note that we do not have the data to conduct a formal cost-effectiveness analysis in Table 8. In particular, the benefits calculated in Table 8 are an underestimate of the social benefits because they do not include the benefits to the patients from being able to return to normal activities sooner or the psychic or physical benefits from fewer complications. In addition, with regard to policies that could lead to reduced turnover and increased unit tenure, the benefit estimates in Table 8 do not include the additional benefits to the VA from a reduction in recruitment and training costs.

\section{Conclusions}

This paper contributes to the literature on the relationship between human capital and performance by using a uniquely detailed dataset on nursing units within hospitals. Since nursing units are small and nurses share responsibility for patient care, this is an excellent setting for studying the relationship between human capital and performance where the work is performed by a team. Widely accepted measures of nursing-sensitive patient outcomes are linked to characteristics of the nursing team that measure its general, hospital-specific, and unit-or-teamspecific human capital. 
This is the first paper to use longitudinal monthly data on nursing units to measure the relationships between the human capital characteristics of the nursing team and patient outcomes. We are able to do this because we use data from the Veterans Administration (VA) hospital system which, unlike the data for other hospital systems, enables us to link the patients to the nursing units in which they were treated. Since we use monthly, not annual, data, we are able to avoid the omitted variable bias and endogeneity bias that could result when annual data on staffing and nurse characteristics are used. With these unique monthly data we are able to provide convincing estimates of the impact of various dimensions of nurse human capital on patient outcomes.

Our results show that the human capital attributes of nursing teams are significant determinants of patient outcomes. Patients' lengths of stay in the hospital are significantly shorter if the patients are cared for by a team of nurses that has more general human capital, as measured by the percentage of nursing hours provided by RNs. With regard to specific human capital, we find that unit or team-specific human capital is a much more important determinant of patient outcomes than hospital-specific human capital. Further evidence of the importance of specific human capital is that patient outcomes worsen when the share of nursing hours provided by contract nurses increases. Calculations of the costs and benefits of policies that increase the specific human capital of the nursing team show that these policies are cost-effective. These findings demonstrate the important role played by human capital in the delivery of healthcare. 


\section{REFERENCES}

AHRQ (2003). AHRQ Quality Indicators: Guide to Patient Safety Indicators (Rep. No. 03-R203). Rockville, MD: Agency for Healthcare Research and Quality.

Aiken, L. H., Clarke, S. P., Sloane, D. M., Sochalski, J., \& Silber, J. H. (2002). "Hospital Nurse Staffing and Patient Mortality, Nurse Burnout, and Job Satisfaction." Journal of the American Medical Association, 288: 1987-1993.

Abraham, K.G., Farber, H.S. (1987). "Job Duration, Seniority, and Earnings," American Economic Review 77: 278-97.

Altonji, J., Shakotko, R. (1987). "Do Wages Rise with Job Seniority?" Review of Economic Studies 54: 437-59.

Autor, D. (2009). "Studies of Labor Market Intermediation: Introduction," in D. Autor (ed), Studies of Labor Market Intermediation, National Bureau of Economic Research, Chicago, 2009.

Bandiera, O., Barankay, I. and Rasul, I. (2005). "Social Preferences and the Response to Incentives: Evidence from Personnel Data", The Quarterly Journal of Economics 120: 917-62.

Bandiera, O., Barankay, I. and Rasul, I. (2011). "Team Incentives: Evidence from a Field Experiment", unpublished.

Bartel, A.P.,Ichniowski, C., Shaw,K (2007). "How Does Information Technology Affect Productivity? Plant-Level Comparisons of Product Innovation, Process Improvement and Worker Skills", The Quarterly Journal of Economics 122: 1721-1758.

Black, S.E., Lynch, L.M.(2001). "How to Compete: The Impact of Workplace Practices and Information Technology on Productivity," Review of Economics and Statistics 83: 434-445.

Blegen, M. A., Goode, C. J., Reed, L. (1998). "Nurse Staffing and Patient Outcomes." Nursing Research, 47:43-50.

Blythe, J., Baumann, A., Giovannetti, P. (2001). 'Nurses' Experiences of Restructuring in Three Ontario Hospitals." Journal of Nursing Scholarship, 33: 61-68.

Boning, B., Ichniowski, C., Shaw, K. (2007). "Opportunity Counts: Teams and the Effectiveness of Production Incentives." Journal of Labor Economics, 25: 613-650.

Butt, M., Baumann, A., O'Brien-Pallas, L., Deber, R., Blythe, J., DiCenso, A. (2002). "The Learning Needs of Nurses Experiencing Job Change." The Journal of Continuing Education in Nursing, 33: 67-73.

Chillemi, O. and Gui, B. (1997). "Team Human Capital and Worker Mobility", Journal of Labor Economics 15: 567-585. 
Cook, A., Gaynor, M., Stephens, M., Taylor, L. (2010). "The Effect of Hospital Nurse Staffing on Patient Health Outcomes: Evidence from California's Minimum Staffing Regulation," NBER Working Paper 16077.

Dobkin, C. (2003). "Hospital Staffing and Inpatient Mortality," unpublished manuscript.

Doyle, J., Ewer, S. Wagner, T. (2010). "Returns to Physician Human Capital: Analyzing Patients Randomized to Physician Teams", Journal of Health Economics 29:866-82.

Elixhauser, A., Steiner, C., Harris, DR, Coffe, RM (1998). "Comorbidity Measures for Use with Administrative Data," Medical Care, 36:8-27.

Evans, W., Kim, B. (2006). "Patient Outcomes When Hospitals Experience a Surge In Admissions." Journal of Health Economics 25:365-88.

Fallik, D. (2005). "Some Hospitals Reconsider Use of Temp Nurses.” Philadelphia Inquirer Online (posted July 10). [URL: http://go.philly.com]

Fox, J.T. and Smeets, V. (2011). "Does Input Quality Drive Measured Differences in Firm Productivity?". NBER Working Paper No. 16853

Furukawa, M.F., Raghu, T.S., B. Shao (2010), "Electronic Medical Records, Nurse Staffing, and Nurse-Sensitive Patient Outcomes: Evidence form the National Database of Nursing Quality Indicators," Medical Care Research and Review, 20:1-21.

Garicano, L., T. Hubbard (2007), "The Return to Knowledge Hierarchies", NBER Working Paper No. 12813.

Gathmann, C., Schonberg,U. (2010)."How General is Human Capital? A Task-Based Approach". Journal of Labor Economics 28: 1-49.

Gruber, J. and S. Kleiner (2011), "Do Strikes Kill?" American Economic Journal: Economic Policy, forthcoming.

Guadalupe, M. (2003), "The Hidden Costs of Fixed Term Contracts: The Impact on Work Accidents," Labour Economics 10:339-357.

Hamilton, B., Nickerson, J. and Owan, H. (2003). "Team Incentives and Worker Heterogeneity: An Empirical Analysis of the Impact of Teams on Productivity and Participation." Journal of Political Economy, 111:465-497.

Herrmann, M. and Rockoff, J. (forthcoming). "Worker Absence and Productivity: Evidence from Teaching, Journal of Labor Economics.

Huckman, R. S. and Pisano, G.P. (2006), "The Firm Specificity of Individual Performance: Evidence from Cardiac Surgery, "Management Science 52: 473-488.

Ichniowski, C. and Shaw, K. (2009), "Connective Capital as Social Capital: The Value of Problem-Solving Networks for Team Players in Firms," NBER Working Paper No. 15619, December. 
Ichniowski, C., Shaw, K, Prennushi, G. (1997). "The Effects of Human Resource Management Practices on Productivity: A Study of Steel Finishing Lines, " American Economic Review 87:291-313.

Kalisch, B., Landstrom, G., Williams R (2009). "Missed Nursing Care: Errors of Omission," Nursing Outlook 57: 3-9.

Kane, R.L, Shamlilyan, T.A., Mueller, C., Duval, S. and Wilt, T.J. (2007). The Association of Registered Nurse Staffing Levels and Patient Outcomes: Systematic Review and Meta-Analysis, Medical Care 45: 1195-1204.

Kambourov, G,, Manovskii, I. (2009). "Occupational Specificity of Human Capital." International Economic Review 50: 63-115.

Mark, B., Harless, D., McCue, M., Yihua, X. (2004). "A Longitudinal Examination of Hospital Registered Nurse Staffing and Quality of Care." Health Services Research, 39:279-299.

National Commission of VA Nursing, 2002-2004 (2004). Caring for America's Veterans: Attracting and Retaining a Quality VHA Nursing Workforce. Department of Veterans Affairs.

National Quality Forum (NQF) (2004). National Voluntary Consensus Standards for Nursing-Sensitive Care: An Initial Performance Measure Set. Washington, D.C.: National Quality Forum.

Neal, D. (1995). "Industry-Specific Human Capital: Evidence from Displaced Workers." Journal of Labor Economics 13:653-77.

Needleman, J., Buerhaus, P., Mattke, S., Stewart, M., Zelevinsky, K. (2002). NurseStaffing Levels and the Quality of Care in Hospitals. New England Journal of Medicine 346: $1715-1722$.

Needleman, J., Buerhaus, P., Pankratz V.S., Leibson, C.L., Stevens, S.R., Harris, M. (2011). "Nurse Staffing and Inpatient Hospital Mortality". New England Journal of Medicine. 364, pp. 1037-45.

Parent, D. (2000). "Industry-Specific Capital and the Wage Profile: Evidence from the National Longitudinal Study of Income Dynamics." Journal of Labor Economics 18: 306-23.

Propper, C. and Van Reenen, J. (2010). "Can Pay Regulation Kill? Panel Data Evidence on the Effect of Labor Markets on Hospital Performance," Journal of Political Economy, 118: $222-273$.

Rebitzer, J. (1995). "Job Safety and Contract Workers in the Petrochemical Industry," Industrial Relations, 34: 40-58.

Rivkin, S., Hanushek, E.A., Kain, J.F. (2005). "Teachers, Schools, and Academic Achievement," Econometrica, 73: 417-458. 
Rockoff, J. (2004). "The Impact of Individual Teachers on Student Achievement: Evidence from Panel Data," AEA Papers and Proceedings, 94: 247-252.

Rodgers J, Lutz S. Cost of Caring: Key Drivers of Growth in Spending on Hospital Care. Washington, DC: Price Waterhouse Coopers; 2003.

Sales, A., Sharp, N., Li, Y. F., Lowy, E., Greiner, G., Liu, C. F. et al. (2008). "The Association Between Nursing Factors and Patient Mortality in the Veterans Health Administration: The View From the Nursing Unit Level", Medical Care 46: 938-945.

Silber, J. Romano, P., Rosen, A., Wang, Y., Even-Shoshan, O. and K. Volpp. (2007). "Failure to Rescue: Comparing Definitions to Measure Quality of Care, " Medical Care, 45: 918925.

Staiger, D., Spetz, J., Phibbs, C.S. (2010). "Is There Monopsony in the Labor Market? Evidence From a Natural Experiment." Journal of Labor Economics 28: 211-236.

Topel, R. (1991). "Specific Capital, Mobility and Wages: Wages Rise with Job Seniority." Journal of Political Economy 99:145-76.

Unruh, L. (2003). "Licensed Nurse Staffing and Adverse Events in Hospitals." Medical Care 41:142-152. 
Figure 1: Month-to-Month Within-Unit Variation ${ }^{\mathrm{a}}$
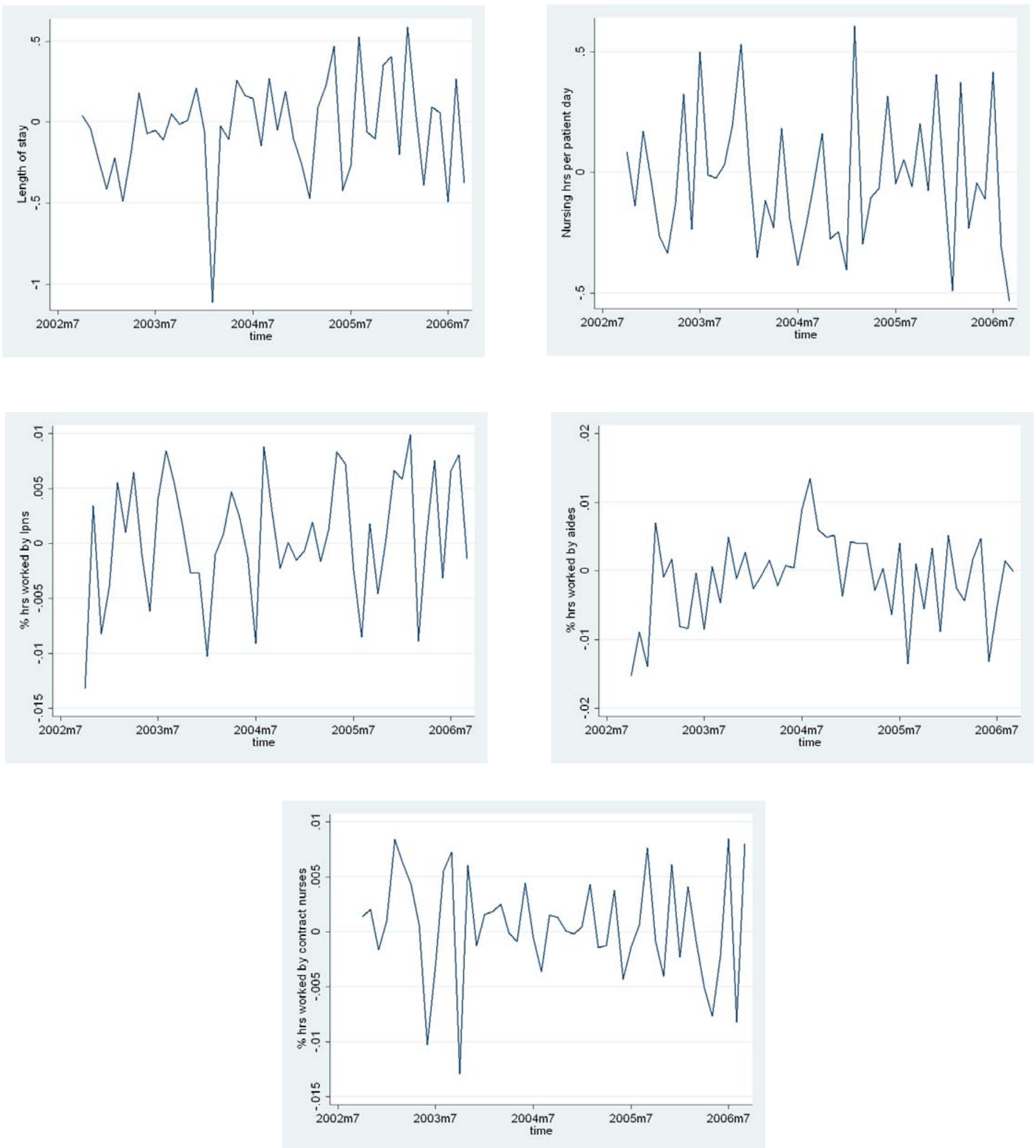
Figure 1, continued
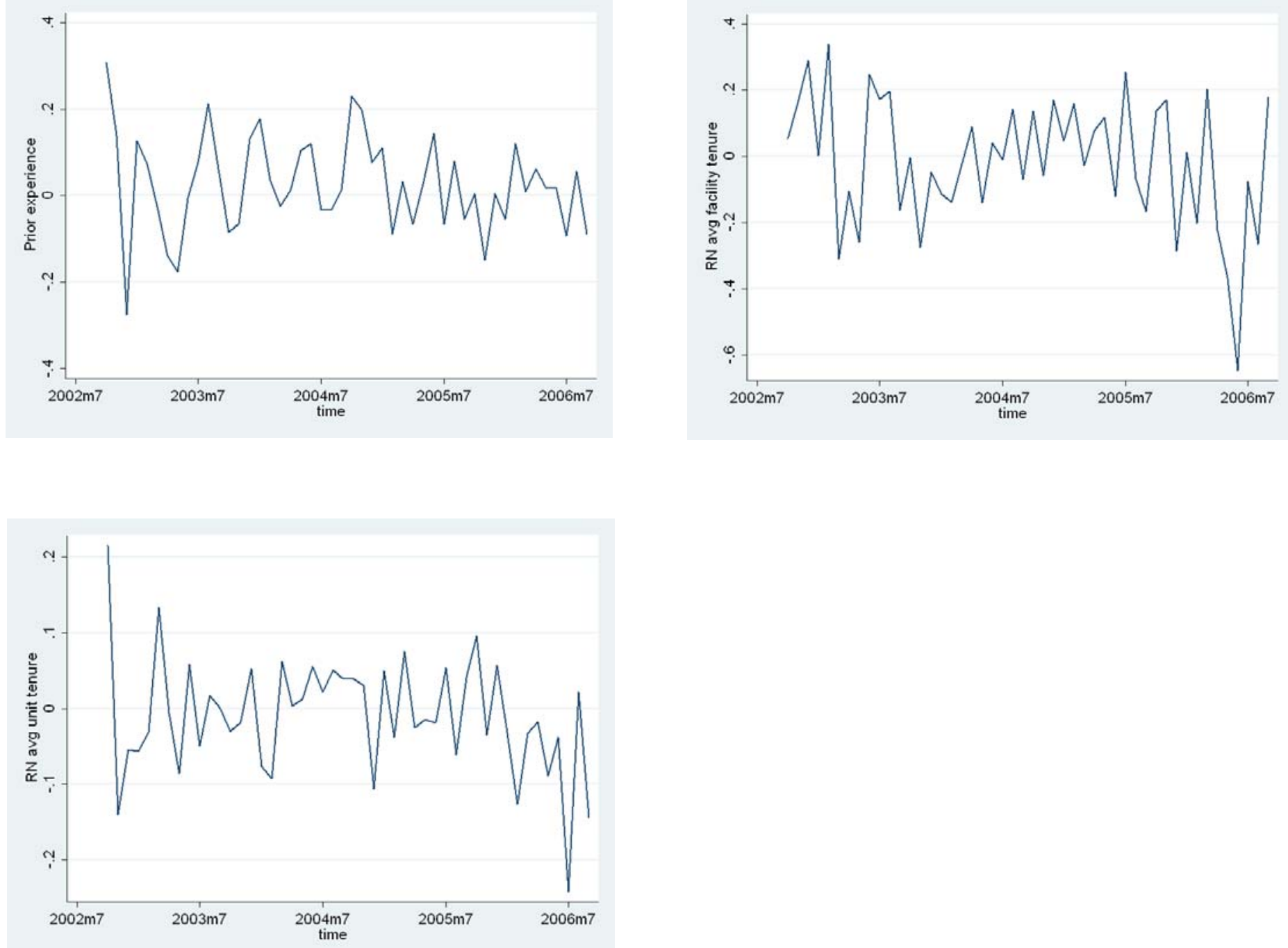

${ }^{\mathrm{a}}$ These plots show the month-to-month within-unit residual variation after controlling for the annual unit fixed effect and the month time dummy. 
Figure 2: Coefficients and 95\% Confidence Intervals on Unit Tenure Spline

Panel A: Uses Column (5) in Table 3

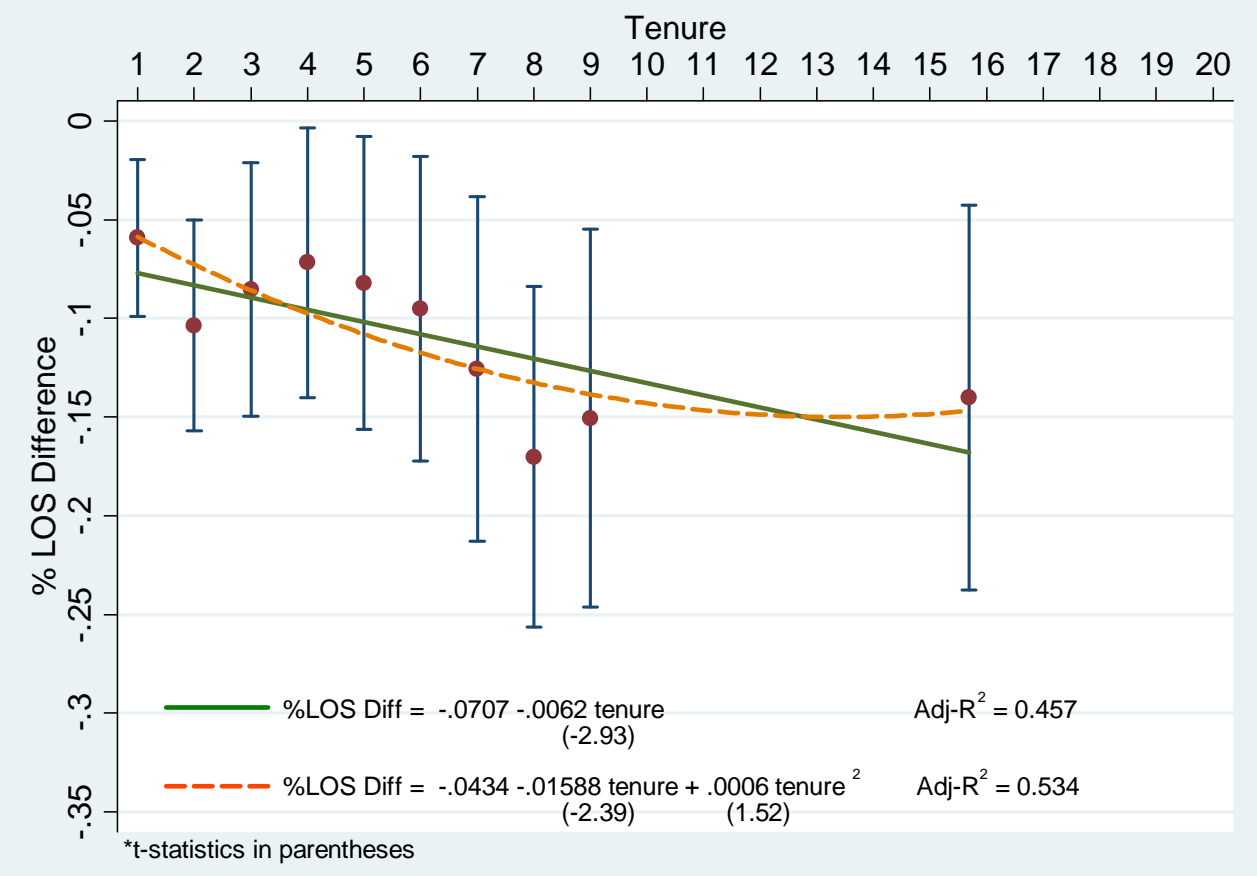

Panel B: Alternative Spline That Combines 8-9 and 9-10 (not reported in Table 3)

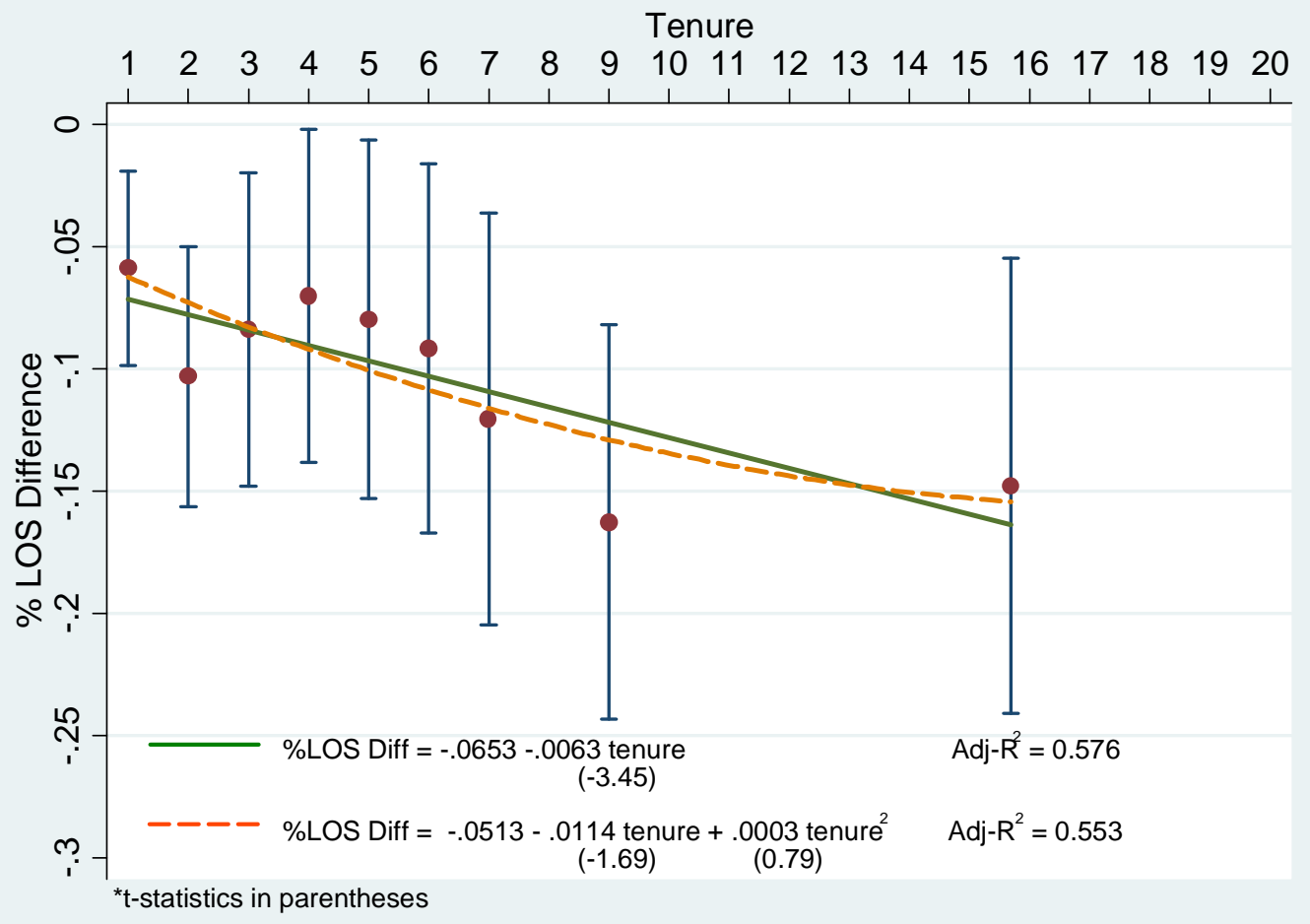


Table 1: Summary Statistics, Fiscal Years 2003-2006

\begin{tabular}{|c|c|c|c|c|}
\hline \multicolumn{5}{|c|}{ ndard Deviation $^{a}$} \\
\hline & Mean & Overall & Between & Within \\
\hline \multicolumn{5}{|l|}{ Patient-Level Variables $(\mathrm{N}=\mathbf{1}, \mathbf{5 6 8 , 0 3 4 )}$} \\
\hline Length of Stay & 6.08 & 8.91 & 1.72 & 8.80 \\
\hline Incidence of Complications & 0.02 & 0.13 & 0.01 & 0.13 \\
\hline Patient Age & 65.72 & 12.68 & 2.22 & 12.51 \\
\hline Medicare Expected LOS & 5.25 & 2.70 & 0.96 & 2.59 \\
\hline Elixhauser Index & 1.45 & 1.09 & 0.25 & 1.07 \\
\hline \multicolumn{5}{|l|}{ Unit-Level Variables $(\mathrm{N}=15418)$} \\
\hline Nursing Hours per Patient Day & 12.59 & 6.30 & 5.94 & 2.04 \\
\hline Percent Nursing Hours by LPNs & 0.14 & 0.15 & 0.15 & 0.03 \\
\hline Percent Nursing Hours by UAPs & 0.11 & 0.11 & 0.11 & 0.03 \\
\hline Percent Nursing Hours by Contract Nurses & 0.02 & 0.06 & 0.05 & 0.03 \\
\hline Average RN Unit Tenure (yrs) & 4.00 & 1.40 & 1.39 & 0.27 \\
\hline Average RN Unit Tenure (yrs; censoring corrected) & 5.23 & 2.25 & 2.23 & 0.37 \\
\hline Avg RN Facility Tenure (yrs) & 7.43 & 2.94 & 2.93 & 0.52 \\
\hline Avg RN Years of Prior Experience & 4.12 & 2.12 & 2.11 & 0.51 \\
\hline Pct RN hrs $0-1$ yrs unit tenure & 0.23 & 0.16 & 0.15 & 0.06 \\
\hline Pct RN hrs $1-2$ yrs unit tenure & 0.14 & 0.12 & 0.10 & 0.06 \\
\hline Pct RN hrs 2-3yrs unit tenure & 0.11 & 0.09 & 0.08 & 0.05 \\
\hline Pct RN hrs 3-4 yrs unit tenure & 0.08 & 0.08 & 0.07 & 0.05 \\
\hline Pct RN hrs $4-5$ yrs unit tenure & 0.07 & 0.08 & 0.07 & 0.04 \\
\hline Pct RN hrs 5-6 yrs unit tenure & 0.06 & 0.08 & 0.06 & 0.04 \\
\hline Pct RN hrs 6-7 yrs unit tenure & 0.05 & 0.08 & 0.06 & 0.05 \\
\hline Pct RN hrs 7-8 yrs unit tenure & 0.05 & 0.08 & 0.08 & 0.05 \\
\hline Pct RN hrs $8-9$ yrs unit tenure & 0.04 & 0.08 & 0.07 & 0.05 \\
\hline Pct RN hrs $9-10$ yrs unit tenure & 0.03 & 0.07 & 0.06 & 0.04 \\
\hline Pct RN hrs $10+$ yrs unit tenure & 0.15 & 0.13 & 0.13 & 0.03 \\
\hline Unit Admissions & 109.13 & 58.12 & 56.79 & 13.20 \\
\hline
\end{tabular}

\footnotetext{
a "Between" and "within" refer to nursing units
} 
Table 2: Randomization Analysis ${ }^{a}$

Dependent Variable
LPN hours/total nursing ho
UAP hours/total nursing hour
Average prior experience
$\%$ contract nursing hours
Average RN unit tenure

Time Dummies

Unit Fixed Effects

Observations

R-squared

Significance Levels: ${ }^{*} p<.10 ;{ }^{* *} p<.05 ;{ }^{* * *} p<.01$

${ }^{a}$ Columns (1) and (3) are random effects estimates.

Columns (2) and (4) include unit fixed effects that vary by year and robust standard errors clustered by unit.
(1)

(3)

(4)

Medicare Expected Medicare Expected Length of Stay Length of Stay

$-0.5914^{* * *}$
$(0.0710)$
$-0.3930^{* * *}$
$(0.0664)$
$0.0210^{* * *}$
$(0.0043)$
$-0.2739^{* * *}$
$(0.0728)$
$0.0428^{* * *}$
$(0.0075)$

Yes

No

$1,568,034$

0.011
$-0.1008$
$(0.1026)$
$-0.1003$
(0.1134)
0.0118
(0.009)
$-0.1446$
(0.1197)
0.0079
(0.0132)

Yes

Yes

$1,568,034$

0.003
Elixhauser

Elixhauser Index

$-0.0468$

(0.0549)

0.0420

$-0.0164$

$-0.0098$

$(0.0463)$

(0.0258)

$-0.0021$

(0.0016)

$(0.0033)$

0.0346

0.0280

(0.0294)

$(0.0430)$

$-0.0051^{*}$

0.0014

(0.0028)

(0.0071)

Yes

Yes

No

Yes

$1,568,034$

$1,568,034$

0.001

0.0002 
Table 3: Nurse Human Capital and Patient's Length of Stay ${ }^{a}$

\begin{tabular}{|c|c|c|c|c|c|c|}
\hline \multicolumn{7}{|l|}{ Staffing } \\
\hline Nursing hours per patient day & $\begin{array}{l}-0.0145^{* * *} \\
(0.0009)\end{array}$ & $\begin{array}{l}-0.0145^{* * *} \\
(0.0009)\end{array}$ & $\begin{array}{l}-0.0145^{* * *} \\
(0.0009)\end{array}$ & $\begin{array}{l}-0.0145^{* * *} \\
(0.0009)\end{array}$ & $\begin{array}{l}-0.0145^{* * *} \\
(0.0009)\end{array}$ & $\begin{array}{l}-0.0151 * * * \\
(0.0009)\end{array}$ \\
\hline \multicolumn{7}{|l|}{ General Human Capital } \\
\hline \multirow[t]{2}{*}{ LPN hours/total nursing hours } & 0.0107 & $-0.0072)$ & 0.0069 & 0.0049 & 0.0072 & 0.0104 \\
\hline & $(0.0413)$ & $(0.0418)$ & $(0.0416)$ & $(0.0416)$ & $(0.0416)$ & $(0.0422)$ \\
\hline UAP hours/total nursing hours & $0.1187^{* * *}$ & $0.1091^{* * *}$ & $0.1188^{* * *}$ & $0.1162^{* * *}$ & $0.1188^{* * *}$ & $0.1185^{* * *}$ \\
\hline Average prior RN experience & $\begin{array}{l}(0.0364) \\
-0.0010 \\
(0.0025)\end{array}$ & $\begin{array}{l}(0.0363) \\
-0.0007 \\
(0.0022)\end{array}$ & $\begin{array}{l}(0.0367) \\
-0.0007 \\
(0.0025)\end{array}$ & $\begin{array}{l}(0.0364) \\
-0.0011 \\
(0.0025)\end{array}$ & $\begin{array}{l}(0.0367) \\
-0.0009 \\
(0.0025)\end{array}$ & $\begin{array}{l}(0.0376) \\
-0.0005 \\
(0.0026)\end{array}$ \\
\hline \multicolumn{7}{|l|}{ Specific Human Capital } \\
\hline$\%$ contract nursing hours & $\begin{array}{l}0.2130 * * * \\
(0.0387)\end{array}$ & $\begin{array}{l}0.2041^{* * *} \\
(0.0388)\end{array}$ & $\begin{array}{l}0.2153^{* * *} \\
(0.0386)\end{array}$ & $\begin{array}{l}0.2105^{* * *} \\
(0.0386)\end{array}$ & $\begin{array}{l}0.2155^{* * *} \\
(0.0386)\end{array}$ & $\begin{array}{l}0.2355^{* * *} \\
(0.0376)\end{array}$ \\
\hline Avg RN fac. ten - avg RN unit ten. & $\begin{array}{c}0.0028) \\
(0.00280\end{array}$ & & $\begin{array}{c}0.0024 \\
(0.0028)\end{array}$ & $\begin{array}{c}0.0006 \\
(0.0029)\end{array}$ & $\begin{array}{c}0.0014 \\
(0.0029)\end{array}$ & $\begin{array}{l}-0.0003 \\
(0.0030)\end{array}$ \\
\hline Average $\mathrm{RN}$ unit tenure & $\begin{array}{l}-0.0226 * * * \\
(0.0042)\end{array}$ & & & $\begin{array}{l}-0.0130 * * * \\
(0.0030)\end{array}$ & & $\begin{array}{l}-0.0119 * * * \\
(0.0030)\end{array}$ \\
\hline Average $\mathrm{RN}$ facility tenure & & $\begin{array}{l}-0.0049 * * \\
(0.0022)\end{array}$ & & & & \\
\hline \multicolumn{7}{|l|}{$\%$ RN Hours with: } \\
\hline $1-2$ years unit tenure & & & $\begin{array}{l}-0.0592 * * * \\
(0.0203)\end{array}$ & & $\begin{array}{l}-0.0592^{* * *} \\
(0.0203)\end{array}$ & \\
\hline $2-3$ years unit tenure & & & $\begin{array}{l}-0.1038^{* * *} \\
(0.0272)\end{array}$ & & $\begin{array}{l}-0.1036^{* * *} \\
(0.0273)\end{array}$ & \\
\hline $3-4$ years unit tenure & & & $\begin{array}{l}-0.0860 * * * \\
(0.0327)\end{array}$ & & $\begin{array}{l}0.0852^{* * *} \\
(0.0378)\end{array}$ & \\
\hline $4-5$ years unit tenure & & & $\begin{array}{l}-0.0731^{* *} \\
(0.0349)\end{array}$ & & $\begin{array}{l}-0.0717^{* *} \\
(0.0349)\end{array}$ & \\
\hline $5-6$ years unit tenure & & & $\begin{array}{l}-0.0842 * * * \\
(0.0379)\end{array}$ & & $\begin{array}{l}-0.0821^{* *} \\
(0.0378)\end{array}$ & \\
\hline $6-7$ years unit tenure & & & $\begin{array}{l}-0.0981 * * * \\
(0.0394)\end{array}$ & & $\begin{array}{l}-0.0952^{* * *} \\
(0.0393)\end{array}$ & \\
\hline $7-8$ years unit tenure & & & $\begin{array}{l}-0.1296^{* * *} \\
(0.0445)\end{array}$ & & $\begin{array}{l}-0.1256^{* * *} \\
(0.0445)\end{array}$ & \\
\hline $8-9$ years unit tenure & & & $\begin{array}{l}-0.1748^{* * *} \\
(0.0439)\end{array}$ & & $\begin{array}{l}-0.1702^{* * *} \\
(0.0441)\end{array}$ & \\
\hline $9-10$ years unit tenure & & & $\begin{array}{l}-0.1566^{* * *} \\
(0.0491)\end{array}$ & & $\begin{array}{l}-0.1505^{* * *} \\
(0.0489)\end{array}$ & \\
\hline$>10$ years unit tenure & & & $\begin{array}{l}-0.1492 * * * \\
(0.0501)\end{array}$ & & $\begin{array}{l}-0.1402^{* * *} \\
(0.0498)\end{array}$ & \\
\hline Average RN Wage & & & & & & $\begin{array}{l}-0.0011 \\
(0.0007)\end{array}$ \\
\hline Constant & $\begin{array}{l}0.8790^{* * *} \\
(0.0310)\end{array}$ & $\begin{array}{l}0.8329 * * * \\
(0.0308)\end{array}$ & $\begin{array}{l}0.8703^{* * *} \\
(0.0306)\end{array}$ & $\begin{array}{l}0.8637 * * * \\
(0,0309)\end{array}$ & $\begin{array}{l}0.8738^{* * *} \\
(0.0306)\end{array}$ & $\begin{array}{l}0.9406 * * * \\
(0.0427)\end{array}$ \\
\hline Observations & $1,568,034$ & $1,568,034$ & $1,568,034$ & $1,568,034$ & $1,568,034$ & $1,568,034$ \\
\hline $\begin{array}{l}\text { R-squared } \\
* p<.10 ; * * p<.05 ; * * * p<.01\end{array}$ & 0.12 & 0.12 & 0.12 & 0.12 & 0.12 & 0.12 \\
\hline
\end{tabular}


Table 4

Impact of Change in Nursing Team on Patient's Length of Stay ${ }^{(a)}$

\section{Staffing}

Nursing hours per patient day

\section{General Human Capital}

LPN hours/total nursing hours

UAP hours/total nursing hours

Average prior $\mathrm{RN}$ experience

\section{Specific Human Capital}

$\%$ contract nursing hours

Avg RN facility tenure - avg RN unit tenure

Average RN unit tenure

\section{Change in Team Composition}

$\mathrm{RN}$ with at least 1 year unit tenure left unit

$\mathrm{RN}$ with at least 5 years unit tenure left unit

RN new to facility joined unit

$\mathrm{RN}$ transferred from another unit

Constant

Observations

R-squared

Significance Levels: ${ }^{*} p<.10 ;{ }^{* *} p<.05 ;{ }^{* * *} p<.01$
(1)

$-0.0145^{* * *}$
$(0.0009)$

0.0059
$(0.0416)$
$0.1166^{* * *}$
$(0.0365)$
-0.0012
$(0.0025)$

$0.2113^{* * *}$

$(0.0387)$

0.0008

(0.0029)

$-0.0124 * * *$

(0.0030)

\section{$0.0045^{* *}$ \\ (0.0023)}

$0.0049^{*}$

(0.0027)

$0.8590^{* * *}$
$(0.0311)$
$1,568,034$
0.12

(2)

$-0.0145^{* * *}$
$(0.0009)$

0.0042
$(0.0416)$
$0.1152^{* * *}$
$(0.0365)$
-0.0010
$(0.0025)$

$0.2095^{* * *}$

(0.0387)

0.0004

(0.0029)

$-0.0130 * * *$

(0.0030)

$0.0046^{* *}$

(0.0023)
(3)

$-0.0145^{* * *}$
$(0.0009)$

0.0042

(0.0416)

$0.1164 * * *$

$(0.0365)$

$-0.0012$

(0.0025)

$0.2108^{* * *}$

(0.0386)

0.0009

(0.0029)

$-0.0121 * * *$

(0.0030)

(4)

$-0.0145^{* * *}$

(0.0009)

0.0025

(0.0416)

$0.1150 * * *$

(0.0364)

$-0.0010$

(0.0025)

$0.2091 * * *$

$(0.0387)$

0.0004

(0.0029)

$-0.0126 * * *$

(0.0030)

$\begin{array}{cc}0.0071^{* *} & 0.0072^{* *} \\ (0.0032) & (0.0032) \\ 0.0049^{*} & \\ (0.0027) & \\ & 0.0013 \\ & (0.0030) \\ 0.8580^{* * *} & 0.8611^{* * *} \\ (0.0311) & (0.0309) \\ 1,568,034 & 1,568,034 \\ 0.12 & 0.12\end{array}$

${ }^{a}$ Dependent variable is $\log ($ patient's length of stay in hospital). All regressions include patient age, Medicare expected length of stay based on the patient's diagnosis (quintile specification), Elixhauser co-morbidity index, number of patient admissions, time dummies for each month, and unit fixed effects that vary by year. Robust standard errors, reported in parentheses, are clustered by nursing unit. Censoring of unit tenure is corrected. 
Table 5: Robustness Checks for Log (Patient's Length of Stay in Hospital) ${ }^{a}$

\section{Staffing}

Nursing hours per patient day

\section{General Human Capital}

LPN hours/total nursing hours

UAP hours/total nursing hours

Average prior $\mathrm{RN}$ experience

\section{Specific Human Capital}

$\%$ contract nursing hours

Avg RN fac. ten. - avg RN unit ten.

Average RN unit tenure

\section{Change in Team Composition}

RN $>=1$ yr unit tenure left unit

$\mathrm{RN}$ new to facility joined unit

\section{Constant}

Observations

$1.053^{* * *}$
$(0.0583)$
401,789

R-squared

0.12

Significance Levels: ${ }^{*} p<.10 ;{ }^{* *} p<.05 ;{ }^{* * *} p<.01$

$-0.0136^{* * *}$
$(0.0015)$

-0.11643
$(0.0814)$
0.0296
$(0.0713)$
0.0010
$(0.0046)$

$0.1960^{* * *}$

(0.0719)

$-0.0172^{* * *}$

(0.0059)

$\begin{array}{cc}\text { Restrict to } & \begin{array}{c}\text { Exclude } \\ \text { Vacation Months }\end{array} \\ \text { Observables }\end{array}$

$-0.0171^{* * *}$

(0.0009)

$-0.0042$

(0.0437)

$0.1187^{* * *}$

(0.0390)

$-0.0003$

(0.0026)

$(0.0056)$

$0.2263 * * *$

$(0.0405)$

0.0001

(0.0031)

$-0.0141^{* * *}$

(0.0031)

Stay Within

$\begin{array}{ll}-0.0132^{* * *} & -0.0094^{* * *} \\ (0.0008) & (0.0010)\end{array}$

0.0008

0.0151

(0.0426)

$0.1011^{* * *}$

(0.0375)

$-0.0006$

(0.0024)

$0.1774^{* * *}$

(0.0385)

0.0014

(0.0029)

$-0.0125^{* * *}$

(0.0030)

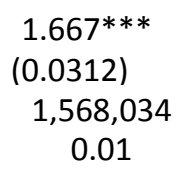

$0.7395 * * *$

$(0.0312)$

$1,394,686$
(3)

Month

(4)

Stay on

(5)

Restrict to

Vacation Months

\section{$-0.0153$}

(0.0763)

$0.1024 *$

(0.0637)

$-0.0021$

(0.0035)

\section{$0.1314 *$}

(0.0733)

0.0071

(0.0050)

$-0.0134^{* * *}$

(0.0054)

$1.685^{* * *}$
$(0.0490)$
399,099
0.11

$-0.0137^{* * *}$
$(0.0015)$

-0.1124
$(0.0809)$
0.0285
$(0.0712)$
0.0008
$(0.0046)$

$0.1980^{* * *}$
$(0.0712)$
-0.0062
$(0.0056)$
$-0.0158^{* * *}$
$(0.0059)$

0.0060
$(0.0055)$
$0.0116^{* *}$
$(0.0061)$

$1.041 * * *$
$(0.0586)$
401,789
0.12

(0.0031)

0.10
(6)

Exclude Observables

$-0.0173^{* * *}$
$(0.0009)$

(0.0009)

\section{$-0.0039$}

(0.0434)

$0.1186^{* * *}$

(0.0392)

$-0.0004$

(0.0026)

\section{$0.2278^{* * *}$}

(0.0408)

0.0003

$-0.0134^{* * *}$

(0.0031)

\subsection{0 *}

(0.0024)

$0.0062^{* *}$

(0.0027)

(7)

Stay Within

Month

$-0.0133^{* * *}$

(0.0009)

0.0157

(0.0426)

$0.1009 * * *$

(0.0376)

$-0.0007$

(0.0024)

$0.1778^{* * *}$

(0.0386)

0.0016

(0.0029)

$-0.0119 * * *$

(0.0030)

$0.0056^{* * *}$

(0.0024)

$0.0045^{*}$

(0.0027)

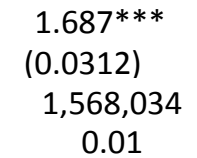

$0.7351 * * *$

(0.0314)

1.394 .686

0.10
(8)

Stay on

Multiple Units

$-0.0093 * * *$

(0.0010)

$-0.0184$

(0.0763)

0.0998

(0.0637)

$-0.0019$

(0.0036)

$0.1289 *$

(0.0734)

0.0066

(0.0050)

$-0.0139 * * *$

(0.0054)

$0.0066^{*}$

(0.0040)

$-0.0020$

(0.0045)

$$
\begin{gathered}
1.687^{* * *} \\
(0.0494) \\
399,099 \\
0.11
\end{gathered}
$$

a The regressions in Columns (1)- (4) correspond to the specification in column (4) of Table 3 and the regressions in columns (5)-(8) correspond to the specification in column (1) of Table 4. In all regressions, unit tenure has been corrected for censoring. All regressions except columns (2) ad (6) include patient age, Medicare expected length of stay based on the patient's diagnosis (quintile specification), Elixhauser co-morbidity index, number of patient admissions, time dummies for each month. Columns (2) and (6) include number of patient admissions and time dummies for each month. All regressions include unit fixed effects that vary by year. Robust standard errors, reported in parentheses, are clustered by nursing unit. 
Table 6: Nurse Human Capital and the Incidence of Complications ${ }^{(a)}$

\begin{tabular}{|c|c|c|c|c|c|c|}
\hline & (1) & (2) & (3) & $(4)^{b}$ & $(5)^{b}$ & $(6)^{b}$ \\
\hline \multicolumn{7}{|l|}{ Staffing } \\
\hline Nursing hours per patient day & $\begin{array}{l}-0.0002 * * \\
(0.0001)\end{array}$ & $\begin{array}{l}-0.0002 * * \\
(0.0001)\end{array}$ & $\begin{array}{l}-0.0002 * * \\
(0.0001)\end{array}$ & $\begin{array}{l}-0.0002 * * \\
(0.0001)\end{array}$ & $\begin{array}{l}-0.0002^{* *} \\
(0.0001)\end{array}$ & $\begin{array}{l}-0.0003^{* * *} \\
(0.0001)\end{array}$ \\
\hline \multicolumn{7}{|l|}{ General Human Capital } \\
\hline LPN hours/total nursing hours & $\begin{array}{c}0.0017 \\
(0.0055)\end{array}$ & $\begin{array}{l}0.0010 \\
(.0055)\end{array}$ & $\begin{array}{c}0.0016 \\
(0.0054)\end{array}$ & $\begin{array}{c}0.0014 \\
(0.0055)\end{array}$ & $\begin{array}{c}0.0016 \\
(0.0055)\end{array}$ & $\begin{array}{c}0.0016 \\
(0.0054)\end{array}$ \\
\hline UAP hours/total nursing hours & $\begin{array}{c}0.0085^{*} \\
(0.0049)\end{array}$ & $\begin{array}{c}0.0081^{*} \\
(0.0049)\end{array}$ & $\begin{array}{c}0.0086^{*} \\
(0.0049)\end{array}$ & $\begin{array}{c}0.0083^{*} \\
(0.0049)\end{array}$ & $\begin{array}{c}0.0084^{*} \\
(0.0049)\end{array}$ & $\begin{array}{l}0.0103^{* *} \\
(0.0051)\end{array}$ \\
\hline Average prior RN experience & $\begin{array}{l}-0.0003 \\
(0.0004)\end{array}$ & $\begin{array}{l}-0.0003 \\
(0.0004)\end{array}$ & $\begin{array}{l}-0.0003 \\
(0.0004)\end{array}$ & $\begin{array}{l}-0.0003 \\
(0.0004)\end{array}$ & $\begin{array}{l}-0.0003 \\
(0.0004)\end{array}$ & $\begin{array}{l}-0.0004 \\
(0.0004)\end{array}$ \\
\hline \multicolumn{7}{|l|}{ Specific Human Capital } \\
\hline$\%$ contract nursing hours & $\begin{array}{c}0.0078 * \\
(0.0047)\end{array}$ & $\begin{array}{c}0.0074 \\
(0.0047)\end{array}$ & $\begin{array}{c}0.0076^{*} \\
(0.0047)\end{array}$ & $\begin{array}{c}0.0076 * \\
(0.0047)\end{array}$ & $\begin{array}{c}0.0076 * \\
(0.0047)\end{array}$ & $\begin{array}{c}0.0076 * \\
(0.0047)\end{array}$ \\
\hline Avg. RN fac.ten.-avg. RN unit ten. & $\begin{array}{c}0.0002 \\
(0.0003)\end{array}$ & & $\begin{array}{c}0.0002 \\
(0.0003)\end{array}$ & $\begin{array}{c}0.0001 \\
(0.0004)\end{array}$ & $\begin{array}{c}0.0002 \\
(0.0004)\end{array}$ & $\begin{array}{c}0.0002 \\
(0.0004)\end{array}$ \\
\hline Average $\mathrm{RN}$ unit tenure & $\begin{array}{l}-0.0009 * \\
(0.0005)\end{array}$ & & & $\begin{array}{l}-0.0004 \\
(0.0004)\end{array}$ & & $\begin{array}{l}-0.0004 \\
(0.0004)\end{array}$ \\
\hline Average RN facility tenure & & $\begin{array}{l}-0.0001 \\
(0.0003)\end{array}$ & & & & \\
\hline \multicolumn{7}{|l|}{$\%$ RN Hours with: } \\
\hline $1-2$ years unit tenure & & & $\begin{array}{l}-0.0037 \\
(0.0027)\end{array}$ & & $\begin{array}{l}-0.0043 \\
(0.0027)\end{array}$ & \\
\hline $2-3$ years unit tenure & & & $\begin{array}{l}-0.0036 \\
(0.0027)\end{array}$ & & $\begin{array}{l}-0.0044 \\
(0.0036)\end{array}$ & \\
\hline 3-4 years unit tenure & & & $\begin{array}{l}-0.0006 \\
(0.0039)\end{array}$ & & $\begin{array}{l}-0.0027 \\
(0.0043)\end{array}$ & \\
\hline $4-5$ years unit tenure & & & $\begin{array}{l}-0.0040 \\
(0.0042)\end{array}$ & & $\begin{array}{l}-0.0054 \\
(0.0047)\end{array}$ & \\
\hline $5-6$ years unit tenure & & & $\begin{array}{l}-0.0023 \\
(0.0046)\end{array}$ & & $\begin{array}{l}-0.0022 \\
(0.0051)\end{array}$ & \\
\hline $6-7$ years unit tenure & & & $\begin{array}{l}-0.0038 \\
(0.0045)\end{array}$ & & $\begin{array}{l}-0.0045 \\
(0.0051)\end{array}$ & \\
\hline \multirow[t]{2}{*}{$7-8$ years unit tenure } & & & -0.0068 & & -0.0049 & \\
\hline & & & $(0.0049)$ & & $(0.0057)$ & \\
\hline \multirow[t]{2}{*}{$8-9$ years unit tenure } & & & $-0.0086^{*}$ & & -0.0080 & \\
\hline & & & $(0.0053)$ & & $(0.0060)$ & \\
\hline $9-10$ years unit tenure & & & $\begin{array}{l}-0.0150^{* *} \\
(0.0063)\end{array}$ & & $\begin{array}{l}-0.0098 \\
(0.0064)\end{array}$ & \\
\hline$>10$ years unit tenure & & & $\begin{array}{l}-0.0029 \\
(0.0080)\end{array}$ & & $\begin{array}{c}0.0002 \\
(0.0065)\end{array}$ & \\
\hline Average RN Wage & & & & & & $\begin{array}{l}-0.0001 \\
(0.0001)\end{array}$ \\
\hline Constant & $\begin{array}{c}0.0016 \\
(0.0042)\end{array}$ & $\begin{array}{l}-0.0003 \\
(0.0041)\end{array}$ & $\begin{array}{c}0.0019 \\
(0.0042)\end{array}$ & $\begin{array}{c}0.0006 \\
(0.0042)\end{array}$ & $\begin{array}{c}0.0012 \\
(0.0042)\end{array}$ & $\begin{array}{c}0.0027 \\
(0.0056)\end{array}$ \\
\hline Observations & $1,568,034$ & $1,568,034$ & $1,568,034$ & $1,568,034$ & $1,568,034$ & $1,568,034$ \\
\hline $\begin{array}{l}\text { R-squared } \\
* p<.10 ; * * p<.05 ; * * * p<.01\end{array}$ & 0.01 & 0.01 & 0.01 & 0.01 & 0.01 & 0.01 \\
\hline
\end{tabular}


Table 7

Impact of Change in Nursing Team on Incidence of Complications ${ }^{(a)}$

\section{Staffing}

Nursing hours per patient day

General Human Capital

LPN hours/total nursing hours

UAP hours/total nursing hours

Average prior $\mathrm{RN}$ experience

\section{Specific Human Capital}

$\%$ contract nursing hours

Avg RN facility tenure - avg RN unit tenure

Average RN unit tenure

\section{Change in Team Composition}

$\mathrm{RN}$ with at least 1 year unit tenure left unit

$\mathrm{RN}$ with at least 5 years unit tenure left unit

RN new to facility joined unit

$\mathrm{RN}$ transferred from another unit

Constant

Observations

R-squared

Significance Levels: ${ }^{*} p<.10 ;{ }^{* *} p<.05 ;{ }^{* * *} p<.01$
(1)

$\begin{array}{cc}-0.0003^{* * *} & -0.0002^{* *} \\ (0.0001) & (0.0001) \\ & \\ 0.0018 & 0.0013 \\ (0.0055) & (0.0055) \\ 0.0086^{*} & 0.0083^{*} \\ (0.0049) & (0.0049) \\ -0.0004 & -0.0003 \\ (0.0004) & (0.0004) \\ & \\ 0.0080^{*} & 0.0076^{*} \\ (0.0047) & (0.0047) \\ 0.0002 & 0.0001 \\ (0.0003) & (0.0004) \\ -0.0002 & -0.0004 \\ (0.0004) & (0.0004) \\ & \\ 0.0004 & 0.0004 \\ (0.0003) & (0.0003)\end{array}$

$0.0012^{* * *}$

(0.0004)

0.0015

(0.0042)

$1,568,034$

0.01

(2)

0.0002

$(0.0004)$

0.0015

$(0.0042)$

$1,568,034$

0.01
(3)

$-0.0003^{* * *}$

(0.0001)

0.0017

$(0.0055)$

$0.0086^{*}$

(0.0049)

$-0.0004$

(0.0004)

$0.0080^{*}$

$(0.0047)$

0.0002

$(0.0004)$

$-0.0002$

$(0.0004)$

0.0006

$(0.0006)$

$0.0012^{* * *}$

(0.0004)

(4)

$-0.0002^{* *}$

$(0.0001)$

0.0012

$(0.0055)$

$0.0083^{*}$

(0.0049)

$-0.0003$

$(0.0004)$

0.0075

$(0.0048)$

0.0001

$(0.0004)$

$-0.0004$

(0.0004)

0.0006

$(0.0006)$

0.0002

$(0.0004)$

$\begin{array}{ll}-0.0006 & 0.0003\end{array}$

$(0.0042) \quad(0.0042)$

$1,568,034$

$1,568,034$

0.01

0.01

${ }^{a}$ Dependent variable is binary indicator for presence of complications. See text for list of complications. All regressions include patient age, Medicare expected length of stay based on the patient's diagnosis (quintile specification), Elixhauser co-morbidity index, number of patient admissions, time dummies for each month, and unit fixed effects that vary by year. Robust standard errors, reported in parentheses, are clustered by nursing unit. 
Table 8: Cost-Benefit Estimates of Various Policy Changes ${ }^{a}$ (calculations are on a per-patient basis)

A. Hours per patient day increases by $10 \%$

$\begin{array}{ll}\text { Benefit } & \$ 281 \\ \text { Cost }^{b} & \$ 291\end{array}$

B. UAP share of nursing hours decreases by 10 percentage points and $\mathrm{RN}$ share increases by 10 percentage points

Benefit $\$ 178$

Cost $^{\mathrm{C}}$ $\$ 168$

C. Contract share of nursing hours decreases by 10 percentage points and $\mathrm{RN}$ share increases by 10 percentage points

Benefit $\$ 323$

Cost $^{d}$

D. RN unit tenure increases by one year

Benefit

$\$ 200$

Cost $^{\mathrm{e}}$ $\$ 168$

\footnotetext{
${ }^{\text {a }}$ Based on coefficients in column 4 of Table 3. The average cost of a day is $\$ 2531$.

${ }^{\mathrm{b}}$ Assumes percentages of $\mathrm{RN}$ hours and non-RN hours remain constant. RN median wages $=\$ 43 ;$ LPN median wages $=\$ 27$ and UAP median wages $=\$ 21$.

${ }^{c}$ Uses RN median wages (\$43) and UAP median wages (\$21).

dUses RN median wage (\$43) and contract nurse median wage (\$37)

${ }^{\mathrm{e}} \mathrm{At}$ the mean of unit tenure, $\mathrm{RN}$ wages increase by $\$ 2 /$ hour for an additional year of unit tenure.
} 


\section{Appendix Table A-1 \\ Determinants of Within-Unit Variance of Hours Per Patient Day}

\section{Independent Variables ${ }^{a}$}

1. Acuity Controls Only ${ }^{\mathrm{c}}$

2. Acuity Controls, LOS

3. Acuity Controls, Admissions

4. Acuity Controls, Nursing Hours

5. Acuity Controls, Admissions,LOS

6. Acuity Controls, Nursing Hours, LOS

7. Acuity Controls, Admissions, Nursing Hours

8. Acuity Controls, Admission, Nursing Hours, LOS
Within-Unit $\mathbf{R}^{2}$

(1) ${ }^{\text {b }}$

(2) ${ }^{b}$

LOS 1/LOS

0.070

0.078

0.113

0.099

0.262

0.109

0.145

0.271

0.313

0.350

0.366

0.364

${ }^{a}$ In addition to the variables shown in each line, all regressions include unit fixed effects and month time dummies

${ }^{b}$ In column (1), rows that include LOS used LOS while in column (2), rows that include LOS used the inverse of LOS.

'Acuity controls are Medicare expected length of stay based on the patient's diagnosis upon admission.

Elixhauser et.al. (1998) index of co-morbidities, and patient age. 


\section{Appendix Table A-2}

\section{Regressions on Unit-to-Unit Mobility of RNs ${ }^{\text {a }}$}

\section{Nurse Characteristics}

Tenure on Unit

Age

Dummy for Bachelor's Degree

Unit Characteristics

Average length of stay ${ }^{c}$

Nursing hours per patient day

LPN hours/total nursing hours

UAP hours/total nursing hours

Contract hours/total nursing hours

Patient acuity ${ }^{b}$

Observations

R-squared
(1)

(2)

(3)

$\begin{array}{lll}-0.0004 * * * & -0.0004 * * * & -0.0004 * * * \\ (0.00004) & (0.00004) & (0.00004) \\ -0.0001 * * * & -0.0001 * * * & -0.0001 * * * \\ (0.00001) & (0.00001) & (0.00001) \\ 0.0006 & 0.0006 & 0.0006 \\ (0.0006) & (0.0006) & (0.0006)\end{array}$

$-0.0001$

0.0001

0.0003

(0.001)

(0.001)

(0.0008)

0.0001

(0.0001)

$-0.0171 * *$

(0.0085)

$-0.0103$

$(0.0064)$

$-0.0132 * *$

(0.0061)

No
358,078
0.001

Yes
358,078
0.001

Significance Levels: ${ }^{*} p<.10 ;{ }^{* *} p<.05 ; * * * p<.01$

${ }^{a}$ Each observation is a nurse-month. Dependent variable equals one if the nurse is working in a different unit in month $t+1$ compared to the unit he/she worked in month $t$. Unit characteristics are measured at month $t$. All regressions include time dummies for each month, and a unit fixed effect that varies by year. Robust standard errors in parentheses.

${ }^{\mathrm{b}}$ Average patient age, average Elixhauser index and Medicare average expected LOS based on patient diagnosis at admission.

${ }^{\mathrm{c}}$ Average hospital length of stay for patients admitted to this unit. This variable is divided by 10. 
Appendix Table A-3

Results of Box-Pierce Test

Length of Stay

Nursing Hours per Patient Day

LPN Hours / Nursing Hours

Aide Hours / Nursing Hours

Contract Hours / Nursing Hours

Prior Experience

Average RN Facility Tenure

Average RN Unit Tenure
Box-Pierce

13.44

15.08

18.88

25.63

15.39

23.93

17.68

13.32 p-value

0.96

0.89

0.76

0.37

0.91

0.47

0.82

0.96 